\title{
Precautionary Savings in Stocks and Bonds
}

\section{Citation}

Pflueger, Carolin E., Emil Nuwan Siriwardane, and Aditya Vikram Sunderam. "Precautionary Savings in Stocks and Bonds." Harvard Business School Working Paper, No. 17-040, November 2016.

\section{Permanent link}

http://nrs.harvard.edu/urn-3:HUL.InstRepos:30907884

\section{Terms of Use}

This article was downloaded from Harvard University's DASH repository, and is made available under the terms and conditions applicable to Open Access Policy Articles, as set forth at http:// nrs.harvard.edu/urn-3:HUL.InstRepos:dash.current.terms-of-use\#OAP

\section{Share Your Story}

The Harvard community has made this article openly available.

Please share how this access benefits you. Submit a story.

\section{Accessibility}




\section{Precautionary Savings in Stocks and Bonds}

Carolin Pflueger Emil Siriwardane Adi Sunderam

Working Paper 17-040 


\section{Precautionary Savings in Stocks and Bonds}

\section{Carolin Pflueger}

University of British Columbia

Emil Siriwardane

Harvard Business School

Adi Sunderam

Harvard Business School

Working Paper 17-040 


\title{
Precautionary Savings in Stocks and Bonds*
}

\author{
Carolin Pflueger $^{\dagger} \quad$ Emil Siriwardane ${ }^{\ddagger} \quad$ Adi Sunderam ${ }^{\S}$
}

November 21, 2016

\begin{abstract}
We document a strong and robust relation between the one-year real rate and precautionary savings motives, as measured by the stock market. Our novel proxy for precautionary savings, based on the difference in valuations between low- and highvolatility stocks, explains $37 \%$ of variation in the real rate. In addition, the real rate forecasts returns on the low-minus-high volatility portfolio, though it appears unrelated with measures of the quantity of risk. Our results suggest that precautionary savings motives, and thus the real rate, are driven by time-varying attitudes towards risk. We rationalize these findings in a stylized model with segmented investor clienteles and habit formation.
\end{abstract}

${ }^{*}$ We thank Hanno Lustig and seminar participants at the University of British Columbia for helpful comments. Pflueger gratefully acknowledges funding from the Social Sciences and Humanities Research Council of Canada (grant number 430-2014-00796). The Online Appendix to the paper can be found here and the Data Appendix can be found here.

${ }^{\dagger}$ Pflueger: University of British Columbia. E-mail: carolin.pflueger@sauder.ubc.ca

${ }_{\ddagger}^{\ddagger}$ Siriwardane: Harvard Business School. E-mail: esiriwardane@hbs.edu.

§ Sunderam: Harvard Business School and NBER. E-mail: asunderam@hbs.edu. 


\section{Introduction}

What drives real interest rates? In recent years, this question has received renewed attention because of unusually low interest rates across the developed world. Traditional explanations of real rate variation generally fall into two broad categories. The first is changes in the expected growth rate of the economy, which may occur because of supply- or demandinduced shifts in productivity growth (e.g. Summers (2015); Gordon (2015); Eggertsson et al. (2016)). The second determinant of real rate variation is precautionary savings, which may vary due to changing uncertainty about the future or changing aversion to uncertainty (e.g. Hall (2016), Cochrane (2016)). In this paper, we provide evidence from the stock market showing that the precautionary savings channel has historically played a major role in driving real interest rates. Moreover, we provide evidence that variation in aversion to uncertainty is a central reason that the economy's desire for precautionary savings is itself moving around.

Understanding what drives variation in the real rate - a key asset price for consumption, investment, and savings decisions - is fundamental to finance and macroeconomics. The precautionary savings motive, in turn, is important for understanding the origins of business cycles, the effectiveness of conventional and unconventional monetary policy, and firms' cash holdings. ${ }^{1}$ Measuring variation in the precautionary savings motive is a difficult challenge. The standard approach relies on estimating volatilities of income or consumption and relating them to investment and savings decisions (e.g. Carroll and Samwick (1998); Lusardi (1998); Banks et al. (2001); Parker and Preston (2005)).

Our key empirical innovation is to use the cross section of stock market valuation ratios to shed light on the strength of the precautionary savings motive at a given point in time. In particular, we proxy for the strength of the precautionary savings motive with investors' attitudes towards volatility, as measured by the difference in book-to-market ra-

\footnotetext{
${ }^{1}$ See, e.g., Bloom (2009); Bloom et al. (2014); Cochrane (2016); Laubach and Williams (2003); McKay, Nakamura, and Steinsson (2016); Holston, Laubach, and Williams (2016); Riddick and Whited (2009); Duchin et al. (2016).
} 
tios between stocks with low volatility and stocks with high volatility (henceforth "Vol-BM spread"). Relying on asset prices is advantageous because they automatically aggregate over different agents in the economy and are available at a much higher frequency than income or consumption. Asset prices are also unique in that they allow us to estimate investors' willingness to pay to avoid volatility at a given point in time.

We begin by establishing several novel empirical facts about the relationship between real rates and the cross section of stocks. First, we show that the book-to-market spread between high and low volatility stocks is strongly correlated with the real rate, measured as the 1-year Treasury bill rate net of survey expectations of 1-year inflation. The relationship is strong in both levels and changes and is strongly economically significant. The headline result of the paper is that the Vol-BM spread explains $37 \%$ of the variation in the real rate.

Our emphasis on the cross section is important, as the valuation of the aggregate market has little explanatory power for the real rate. Our particular focus on equity volatility is also critical. Real rate variation is not explained by valuation-ratio spreads generated from sorting stocks based on size, value, duration of cash flows, cash flow beta or CAPM beta - all characteristics that are known to describe the cross section of stock returns. ${ }^{2}$ Furthermore, the ability of the Vol-BM spread to explain real rate variation remains after we account for changes in macroeconomic uncertainty (e.g., total factor productivity volatility) and changes in survey expectations of macroeconomic growth.

We then delve deeper into what drives the relationship between the real rate and the VolBM spread. Standard present value identities point to two possible explanations. Changes in the Vol-BM spread must reflect either differential changes in expected cash flow growth or differential changes in expected returns between low- and high-volatility stocks. In other words, the real rate may correlate with the Vol-BM spread because it loads on factors that drive expected cash flow growth or factors that determine expected returns. The data points to expected returns, as the real rate forecasts future returns on a portfolio that is long low

\footnotetext{
${ }^{2}$ The relative valuation of small and big stocks does seem to possess some explanatory power but is subsumed by the Vol-BM spread.
} 
volatility stocks and short high volatility stocks. This fact implies that the factors driving expected returns on volatility-sorted portfolios also drive real rate variation.

Taken together, these pieces of evidence paint a clear picture. The book-to-market spread between low and high volatility stocks captures the compensation investors' demand for bearing uncertainty, and thus their demand for precautionary savings. The relationship between the Vol-BM spread and the real interest rate thus implies that variation in precautionary savings drives movements in the real rate.

We next explore why investor compensation for bearing uncertainty varies over time. Changes in expected returns must reflect either changing investor aversion to volatility or changing quantities of volatility. We look for evidence that the real rate is correlated with changing quantities of risk and find none. Real rates are not consistently contemporaneously correlated with the difference in realized volatilities of low- and high-volatility stocks or the realized volatility of the aggregate stock market. Furthermore, real rates do not forecast realized volatility of volatility-sorted stocks or the realized volatility of the aggregate stock market. Finally, the forecasting power of the real rate for returns on the long-short portfolio sorted on volatility is not impacted by controlling for volatility itself. These results suggest that variation in the precautionary savings motive, and thus variation in the real rate, is driven by changing investor aversion to volatility rather than changing quantities of volatility.

In summary, we present novel empirical evidence that time variation in the real rate is strongly correlated with time variation in the cross sectional price of volatility in stocks. We then write down a model to help rationalize these findings. The model serves two key purposes. First, it provides an explanation for why the valuations of volatility-sorted stock portfolios are informative about the strength of the precautionary savings motive, even though aggregate market valuations are not. Second, it allows us to understand whether the magnitudes of the correlations we observe in the data are reasonable.

In the model, idiosyncratic risk is priced, because markets are segmented and investors are imperfectly diversified, consistent with the empirical link between household income 
risk and idiosyncratic stock return volatility (Herskovic et al. (2016)), and employees' bias towards their own employer's stock in 401(k) plans (Benartzi (2001)). Investors derive utility from consumption relative to slowly-moving habit (Campbell and Cochrane (1999); Menzly et al. (2004)), generating volatile and predictable stock returns as in the data. Investors are borrowing-constrained, so the real risk-free rate is determined by whoever values the riskfree asset most highly, which will typically be investors with highly uncertain consumption streams and strong time-varying precautionary savings motives. A decline in high-volatility consumers' consumption relative to habit raises risk premia and drives down prices of highvolatility stocks relative to low volatility stocks. Simultaneously, this consumption decline increases the risk aversion and precautionary savings motives of marginal savers, driving down the risk-free rate. Book-to-market ratios and expected excess returns for low-minushigh-volatility stocks hence fall at the same time as the risk-free rate. Because marginal investors in the risk-free asset are different from marginal investors of the majority of stocks, the risk-free rate is close to uncorrelated with the aggregate book-to-market ratio, as in the data. In a calibrated version of the model, the relationships between the real riskfree rate, the Vol-BM spread, and future low-minus-high-volatility equity excess returns are quantitatively consistent with the data.

Finally, we consider several alternative models that are consistent with the channel favored by our empirical evidence, generating time-varying attitudes towards volatility and precautionary savings.

Our paper is related to several strands of the literature. On the asset pricing side, it is related to the literature studying the pricing of idiosyncratic risk in the stock market (Ang et al. (2006b, 2009); Johnson (2004); Fu (2009); Stambaugh et al. (2015); Hou and Loh (2016); Herskovic et al. (2016)). While this literature has focused on the average returns on low-volatility stocks over high-volatility stocks, we contribute by studying how the valuation of low-minus-high volatility stocks varies over time. Our findings are consistent with a recent corporate finance literature that attributes high recent corporate cash holdings to a 
precautionary savings motive (Riddick and Whited (2009); Duchin et al. (2016)). Finally, this paper speaks to the literature on monetary policy. Our findings are consistent with McKay et al. (2016), who argue that consumers' precautionary savings motive helps explain why forward guidance by central banks has been less effective in stimulating consumption and spending than standard New Keynesian models might suggest. The paper also contributes to a recent literature in macroeconomics that seeks to estimate the time-varying natural rate of interest (Laubach and Williams (2003); Cúrdia et al. (2015)), that uses either using long-term historical data or dynamic stochastic equilibrium models. Similarly, Hartzmark (2016) uses estimated changes in expected macroeconomic volatility over time to argue that precautionary savings, driven by changing quantities of risk, is an important driver of real interest rates. ${ }^{3}$ In contrast, our approach pins down variation in the precautionary savings motive by using information from the cross section of stocks. Using a stock market based measure of precautionary savings allows us to provide new evidence on the relation between the real rate and the price of idiosyncratic volatility.

The remainder of this paper is organized as follows. Section 2 describes the data and portfolio construction. Section 3 presents the main empirical results. Section 4 describes the model and shows that it can replicate the empirical findings. Section 5 discusses alternative explanations for time-varying attitudes towards volatility. Finally, Section 6 concludes.

\section{Data}

We construct a quarterly data set running from 1973 to 2008. The data set begins with the addition of AMEX stocks to COMPUSTAT and ends in 2008 to avoid problems with statistical inference arising from the fact that real rates have essentially been constant since

\footnotetext{
${ }^{3}$ We do not find a significant relation between variation in volatility itself and the real rate. While this might at first appear in contrast with Hartzmark (2016), we note that our empirical sample is substantively different. We estimate precautionary savings during normal business-cycle fluctuations, while Hartzmark (2016) includes data from the 1930s, when both interest rates and uncertainty experienced very large swings. We can therefore reconcile the results in this paper with Hartzmark (2016) if precautionary savings and the quantity of volatility are unrelated during normal times, but move together during rare episodes of extreme economic fluctuations.
} 
2008. We provide full details of all of the data used in the paper in a separate Data Appendix. Here, we briefly describe the construction of some of our key variables.

\subsection{Construction of Key Variables}

\section{Valuation Ratios}

The valuation ratios used in the paper derive from the CRSP-COMPUSTAT merged database. At the end of each quarter and for each individual stock, we form book-to-market ratios. The value of book equity comes from COMPUSTAT Quarterly and is defined following Fama and French (1993). We assume that accounting information for each firm is known with a one-quarter lag. At the end of each quarter, we use the trailing six-month average of market capitalization when computing the book-to-market ratio of a given firm. This smooths out any short-term fluctuations in market value. We have experimented with many variants on the construction of book-to-market, and our results are not sensitive to these choices.

\section{Volatility-Sorted Portfolio Construction}

At the end of each quarter, we use daily CRSP stock data from from the previous two months to compute equity volatility. We exclude firms that do not have at least 20 observations over this time frame. This approach mirrors the construction of variance-sorted portfolios on Ken French's website (e.g., Ang, Hodrick, Xing, and Zhang (2006a)). We compute each firm's idiosyncratic volatility using the residuals from a regression of ex-dividend firm returns on the Fama and French (1993) factors. We prefer to use idiosyncratic volatility as opposed to total volatility because it strengthens the argument that our results are not driven by exposure to well-known equity risk factors. That said, our results are essentially unchanged if we use total volatility.

At the end of each quarter, we sort firms into quintiles based on their idiosyncratic volatility. At any given point in time, the valuation ratio for a quintile is simply the equalweighted average of the valuation ratios of stocks in that quintile. One of the key variables 
in our empirical analysis is the Vol-BM Spread, the difference between the average bookto-market ratio of stocks in the lowest quintile of idiosyncratic volatility and the average book-to-market ratio of stocks in the highest quintile of idiosyncratic volatility.

Quarterly realized returns in a given quintile are computed in an analogous fashion, aggregated up using monthly data from CRSP.

\section{The Real Rate}

The real rate is the one-year Treasury bill rate net of one-year survey expectations of the inflation (the GDP deflator) from the Survey of Professional Forecasters. We choose a short maturity interest rate, because at this horizon, inflation risk is small, and inflation risk premia are unlikely to affect our measure of the risk-free rate.

\subsection{Summary Statistics}

Table 1 contains basic summary statistics on our volatility-sorted portfolios. The first thing to notice is that, on average, the Vol-BM spread is negative; that is, low volatility stocks have lower book-to-market ratios than high volatility stocks. However, as Fig. 1 shows, this masks considerable variation in the Vol-BM spread. Indeed, the standard deviation of the Vol-BM spread is bigger in absolute value than its mean. This variation is at the heart of our empirical work.

Returns on the low-minus-high volatility portfolio are highly volatile, with an annualized standard deviation of $29.75 \%$. While high-volatility stocks in our sample have high bookto-market, the quintile of the most volatile stocks on average has excess returns that are 1.32 percentage points lower than for the lowest-volatility quintile. This is the well-known idiosyncratic volatility puzzle of Ang et al. (2006b) and Ang et al. (2009). A number of explanations have been proposed in the literature, ranging from shorting constraints (Stambaugh et al. (2015)) to the convexity of equity payoffs (Johnson (2004)). In contrast to those papers, which focus on the average level of returns, our focus is the time-variation 
in low-minus-high volatility stock returns and valuations. While we do not aim to resolve the volatility puzzle, we show that the empirically observed low-minus-high volatility excess returns occur in $14.9 \%$ of simulated model sample paths with a sample size the same as the data.

The second-to-last row of Table 1 shows that high-volatility portfolios load onto the SMB factor, consistent with highly-volatile stocks being smaller on average. Since small stocks are more likely to be traded by individuals rather than institutions (Lee et al. (1991)), it is particularly plausible that investor clienteles for these stocks are segmented, which would strengthen the argument for a link between idiosyncratic volatility and investors' desire for precautionary savings. Given the factor structure of volatility-sorted portfolios, one might be concerned that our results are driven by exposure to Fama-French factors. For this reason, we show that all return predictability results are robust to controlling for contemporaneous Fama-French factor returns.

\section{Empirical Results}

\subsection{Valuation Ratios and the Real Rate}

We begin by documenting the strong empirical relationship between the real rate and the book-to-market spread between low and high volatility stocks. Specifically, we run regressions of the form:

$$
\text { Real } \text { Rate }_{t}=a+b \times \text { Vol-BM Spread } t+\varepsilon_{t},
$$

where the Vol-BM spread is the difference in book-to-market valuations between low and high volatility stocks. Because both the real rate and the Vol-BM spread are persistent, we compute standard errors in multiple ways. Specifically, we compute both Hansen and

Hodrick (1980) and Newey and West (1987) standard errors using 12 lags and report the more conservative $t$-statistic. 
Column (1) of Table 2 shows a strong positive correlation between the real rate and the Vol-BM spread. When market valuations are high, book-to-market ratios are low. Thus, the Vol-BM spread is high when the valuations of high volatility stocks are large relative to low volatility stocks. Column (1) of Table 2 therefore indicates that the real rate tends to be high when investors favor high volatility stocks. Conversely, the real rate tends to be low when investors are averse to high volatility stocks. This is the first piece of suggestive evidence that the Vol-BM spread captures variation in precautionary savings motives.

The magnitude of the effect is large in both economic and statistical terms. A onestandard deviation increase in the Vol-BM spread is associated with a 1.18 percentage point increase in the real rate. This is significant relative to the standard deviation of the real rate, which is 1.94 percentage points. The $R^{2}$ of the univariate regression is $37 \%$, indicating that the Vol-BM spread explains a meaningful fraction of variation in the real rate. Fig. 2 makes this point visually, plotting the time series of the real rate against the fitted value from regression in Eq. (1). The figure also shows that the regression is not driven by outliers - the Vol-BM spread tracks all of the major variation in the real rate since 1970. Fig. 3 displays the same evidence in a scatter plot. The relationship between the real rate and the book-to-market spread is robust and approximately linear throughout the distribution.

Column (2) of Table 2 shows that our focus on the cross section of stock valuations is important. There is no relationship between the book-to-market ratio of the aggregate stock market and the real rate. This is not just an issue of statistical precision; the economic magnitude of the point estimate is much smaller as well: a one-standard deviation increase in the aggregate book-to-market ratio is associated with a 49 basis point increase in the real rate. In column (3) of Table 2, we show that the statistical significance and even the magnitude of the Vol-BM slope coefficient are unchanged when controlling for both the aggregate book-to-market ratio and expected GDP growth from the Survey of Professional Forecasters. We include a measure of expected GDP growth because standard macroeconomic theory suggests that the real interest rate and expected growth should positively comove. If any- 
thing, expected GDP growth enters with the wrong sign, even though the magnitude of the estimated coefficient is small and measured imprecisely. The main takeaway is that the relationship between the real rate and the Vol-BM spread is stable throughout all of these regression specifications.

In Table 3, we rerun the same analysis in changes rather than levels. This helps to ensure that our statistical inference is not distorted by the persistence of either the real rate or the

Vol-BM spread. Because changes in these variables may still be autocorrelated, we again compute both Hansen and Hodrick (1980) and Newey and West (1987) standard errors using six lags and report the more conservative $t$-statistic. Columns (1) to (3) runs our analysis using one-quarter changes, while columns (4) to (6) use four-quarter changes.

Running regression (1) in differences yields very similar results to running it in levels. As is clear from Table 3, changes in the real rate are strongly correlated with changes in the Vol-BM spread. Moreover, the magnitudes and statistical significance of the point estimate on the Vol-BM spread are close to what we observe in Table 2. In contrast, there is little relation between changes in the real rate and changes in the aggregate book-tomarket ratio and expected GDP growth. Overall, the evidence in Tables 2 and 3 indicate a robust relationship - both in economic and statistical terms - between the real rate and the Vol-BM spread. This is the central empirical finding of the paper, and as we show in later sections, these results stand up to the inclusion of a battery of additional control variables and different regression specifications.

\subsection{Returns on Volatility-Sorted Portfolios and the Real Rate}

We next seek to understand what drives the correlation between the real rate and the VolBM spread. At any point in time, the Vol-BM spread simply reflects differences in the valuation of high and low volatility stocks. It is well known that valuation ratios must reflect either expected cash flow growth or expected returns. Thus, the results in Tables 2 and 3 could be driven by growth expectations if the cash flows of high volatility stocks 
are more sensitive to aggregate growth than the cash flows of low volatility stocks. In this case, the Vol-BM spread may line up with the real rate because it is a good proxy for variation in expected aggregate growth. Alternatively, the Vol-BM spread may be driven by changes in the expected returns of low volatility stocks, relative to high volatility stocks. In this case, changes in the compensation investors' demand for bearing uncertainty, and thus their demand for precautionary savings, is a natural explanation for the observed correlation between the real rate and the Vol-BM spread.

To disentangle these two possibilities, we run simple return forecasting regressions. Specifically, we forecast the return on a portfolio that is long low volatility stocks and short high volatility stocks with either the Vol-BM spread or the real rate. Formally, we run:

$$
R_{t \rightarrow t+k}=a+b \times X_{t}+\xi_{t+k}
$$

where $X_{t}$ is either the Vol-BM spread or the real rate. Table 4 contains the results of this exercise. In Panel A, we set $k=1$ and forecast one-quarter ahead returns, while in Panel B we set $k=4$ and forecast four-quarter returns. For regressions with a one-quarter horizon, standard errors are computed using both Newey-West (1987) and Hansen-Hodrick (1980) with five lags, and we report the more conservative t-statistic of the two. For regression with four-quarter horizons, we use Hodrick (1992) standard errors to be maximally conservative in dealing with overlapping returns.

Column (1) of Table 4 Panel A shows that the Vol-BM spread has strong forecasting power for returns on the long-short portfolio. The economic magnitude of the relationship is also strong. A one-standard deviation increase in the spread is associated with a 5.3 percentage point increase in returns on the long-short portfolio. To put this in perspective, the standard deviation of the long-short portfolio is 14.9 percent. Thus, it appears that much of the variation in the Vol-BM spread reflects variation in expected returns, consistent with much of the empirical asset pricing literature (e.g., Cochrane (2011)). 
Column (2) indicates that this forecasting power remains once we control for the contemporaneous realizations of the Fama and French (1993) risk factors. That is, in regression (2), we control for the realized values of the excess return on the aggregate stock market, HML, and SMB at time $t+1$. The forecasting power of the Vol-BM spread survives the inclusion of these controls, suggesting that we are not just picking up the power of the spread to forecast the Fama-French factors - our focus on volatility sorted portfolios is important. However, the magnitude of the coefficient in column (2) is smaller than that in column (1). This reflects the fact that both the Vol-BM spread and the real rate have some forecasting power for excess returns of small stocks (SMB).

Column (3) of Table 4 Panel A makes the connection between the real rate and timevarying expected returns on the volatility-sorted portfolio directly. It demonstrates that the real rate also strongly forecasts returns on the long-short portfolio. When the real rate is high, low volatility stocks tend to do well relative to high volatility stocks going forward. In contrast, a low real rate means investors require a premium to hold high volatility stocks, as evidence by the fact that these stocks tend to do relatively well in the future. A onestandard deviation increase in the real rate is associated with a 3.9 percentage point increase in returns on the long-short portfolio. Thus, movements in the real rate forecast returns on the long-short portfolio nearly as well as movements in the Vol-BM spread. This implies that the correlation between the real rate and the Vol-BM spread documented in Section 3.1 is largely driven by changes in expected returns, not changes in expected cash flow growth.

Column (4) shows that the relationship between the real rate and returns on the longshort portfolio is weakened when we control for the Fama and French (1993) factors. This again reflects the fact that returns on the long-short portfolio, the real rate, and returns on small stocks (SMB) are all correlated.

Panel B of Table 4 shows that we obtain similar results once we move to an annual horizon. The magnitude of the forecasting power of the real rate is again comparable to the forecasting power of the Vol-BM spread. Taken together, we interpret the forecasting 
evidence in Table 4 to mean that variation in the expected return spread between high and low volatility stocks captures precautionary savings, and in turn, is strongly correlated with the real interest rate.

In Table 5, we explore in more depth the relationship between the real rate and the Fama and French (1993) factors. The table shows that the real rate and the Vol-BM spread have little forecasting power for either the aggregate market excess return or value stocks (HML). Again, this highlights the importance of our focus on volatility sorts as a proxy for the strength of the precautionary savings motive. Neither the market excess return nor cross sectional sorts based on valuations (HML) are strongly related to the real rate. In contrast, there is some evidence that the real rate is related to the return spread between small and large market capitalization stocks (SMB). Intuitively, small stocks tend to have high volatility, so the two sorts are somewhat correlated. However, as we discuss further below, the overall evidence suggests that volatility, not size, is the main driver of our results.

\subsection{Prices versus Quantities of Risk}

We next dig deeper into the relationship between the real rate and returns on the long-short portfolio sorted on volatility. Changes in expected returns must reflect either changing prices of risk or changing quantities of risk. In other words, aversion to volatility can be moving around over time or the amount of volatility can be moving around over time. In this section, we look for evidence that the real rate is correlated with changing quantities of volatility. Finding no such evidence in a variety of different tests, we conclude that the relationship between the real rate and returns on the long-short portfolio sorted on volatility is likely driven by changing aversion to volatility.

We begin by showing that the relationship between the real rate and the book-to-market spread is unaffected by controlling for various measures of contemporaneous volatility. Specifically, we run the regression in Eq. (1) and add controls for contemporaneous realized volatility. Our first volatility control is the spread in average realized return volatilities between 
our low volatility portfolio and our high volatility portfolio in quarter $t$. We compute this variable using daily data. To control for macroeconomic volatility, we include the volatility of TFP growth implied from a GARCH model as in Bloom (2009). ${ }^{4}$ In addition, we control for the realized within-quarter volatility of the Fama and French (1993), computed using daily data.

The results are presented in Table 6 . Columns (1) to (3) contain the results in levels, while columns (4) to (6) use four-quarter changes. Column (1) shows that there is no relationship between the real rate and the relative realized volatility of high and low volatility stocks. This suggests that it is unlikely that the relationship we document between the real rate and the Vol-BM spread is driven by changes in the volatilities of our portfolios. Column (2) shows that there is some evidence that the real rate is related to volatility of the aggregate market and volatility of the SMB portfolio. ${ }^{5}$ However, this relationship disappears in column (3) when we include the Vol-BM spread. In columns (4) to (6), we obtain similar results when running the analysis in four-quarter changes. The only variable robustly correlated with the real rate is the Vol-BM spread, whereas the volatility variables have little impact.

The quantity of risk also has no ability to forecast excess returns on the long-short portfolio of volatility sorted stocks. In Table 7, we re-run the forecasting regression from Eq. (2) and add controls for realized volatility in quarter $t$. That is, we forecast returns from one-year ahead returns using the current real rate and the current level of volatility. ${ }^{6}$

Column (1) shows that the spread in average realized return volatilities between our low volatility portfolio and our high volatility portfolio in quarter $t$ has no forecasting power for returns. Column (2) shows the forecasting power of the real rate remains unchanged when we add this spread in average volatility as a control. In the remaining columns, we run horse

\footnotetext{
${ }^{4}$ See Table A.1 of the Online Appendix for further discussion of the estimation of TFP volatility.

${ }^{5}$ The opposite signs of aggregate market volatility and SMB volatility are due to the fact that the two variables have an $82 \%$ correlation. In untabulated results, where we run univariate regressions of the real rate on either aggregate market volatility or SMB volatility, we find no statistically or economically significant relationship.

${ }^{6}$ In untabulated results, we look at the level of realized volatility over the forecast period, $t+1$ to $t+4$, as well as increases in realized volatility from $t$ to $t+4$. None of these permutations affect the forecasting power of the real rate for returns on the long-short portfolio.
} 
races between the real rate and other measures of the quantity of risk: the volatility of TFP growth, the volatility of the market excess return, and the volatilities of the Fama-French factors. None of these measures impacts the forecasting power of the real rate for excess returns on the long-short portfolio of volatility sorted stocks. Column (7) shows a kitchen sink regression where we include all of the quantity of risk measures simultaneously. There is some reduction in the magnitude and statistical significance of the real rate's forecasting power for returns. However, given the results of the univariate horse races in Columns (2) though (6), this likely simply reflects the limited size of the sample relative to the number of covariates in the regression.

Lastly, in Table 8, we try to forecast volatility directly using either the Vol-BM spread or the real rate. Formally, we run:

$$
V o l_{t+1}=a+b \times X_{t}+\epsilon_{t+1},
$$

where $X_{t}$ is either the Vol-BM spread (Panel A) or the real rate (Panel B). Each column examines a different volatility measure, as specified by the column header. For instance, column (1) examines the spread in average realized return volatilities between our low volatility portfolio and our high volatility portfolio, while column (2) examines realized TFP volatility. The Vol-BM spread does not forecast any of the volatility variables we examine in Panel A. Similarly, in Panel B, we find that the real rate does not forecast any of the volatility measures.

Overall, the results presented in Tables 6, 7, and 8 suggest that our results are not driven by changes in the quantity of risk. We cannot directly test for time variation in the price of risk. However, our results are most consistent with the idea that the real rate is strongly correlated with time variation in investor aversion to volatility, not time variation in the quantity of volatility. 


\subsection{Alternative Cross-Sectional Sorts}

We now explore alternative explanations for the empirical relationship between the real rate and stock portfolios sorted on volatility. Specifically, we examine the possibility that volatility is simply correlated with another characteristic that is more important for explaining the real rate. We sort stocks along a variety of dimensions and form book-to-market spreads based on the sorting variable. For instance, when examining size as a characteristic, we sort stocks in quintiles based on their market capitalization, then compute the difference between the book-to-market ratio of the smallest and the largest stocks. We then run the regression in Eq. 1, relating the real rate to the spread in book-to-market based on each sort. ${ }^{7}$

The results are displayed in Table 9. In column (1), we relate the real rate to the spread in book-to-market sorting stocks based on the expected duration of their cash flows. If high volatility stocks simply have higher duration cash flows than low duration cash flows, then their valuations should fall more when real rates rise. ${ }^{8}$ This is one sense in which low volatility stocks may be more "bond-like" than high volatility stocks (e.g., Baker and Wurgler (2012)). ${ }^{9}$ In this case, a mechanical duration effect could explain our results in Table 2. To examine this possibility, we follow Weber (2016) and construct the expected duration of cash flows for each firm in our data. We then sort stocks based on this duration measure and calculate the spread in book-to-market between high and low duration stocks. As column (1)

\footnotetext{
${ }^{7}$ We have also explored an alternative method of ruling out alternative explanations based on double sorts. Specifically, we can construct double sorts based on volatility and another characteristic Y. We then construct a Y-neutral book-to-market spread by sorting stocks on volatility within each tercile of characteristic Y. This spread measures the difference in valuations of low volatility and high volatility stocks that have similar values of characteristic Y. In untabulated results, we find that these double sorted book-to-market spreads are still strongly correlated with the real rate.

${ }^{8}$ This is a particular version of the broader possibility that our results are driven by reverse causality. Our interpretation is that both real rates and the relative valuations of low- and high-volatility stocks are responding to the same factor, precautionary saving. Alternatively, it could be the case that changes in real rates are driving changes in valuations. In addition to examining alternative cross-sectional sorts, we have examined this possibility by examining monetary policy shocks. In untabulated results, we verify that the relationsihp between the real rate and Vol-BM spread is unaffected by controlling for monetary policy shocks, as identified by Romer and Romer (2004), Bernanke and Kuttner (2005)), and McKay et al. (2016). This gives us some comfort that reverse causality is not driving our results.

${ }^{9}$ The alternative sense that low volatility stocks are more bond-like because they are less volatile and idiosyncratic risk matters is exactly what we are trying to capture.
} 
shows, the relationship between this duration spread and the real rate is negative. However, it is insignificant and much smaller in magnitude than the Vol-BM spread.

In columns (2)-(4), we sort stocks based on various measures of traditional "beta". For example, column (2) indicates that the book-to-market spread based on CAPM beta is correlated with the real rate. However, as we show shortly, this mostly reflects the fact that CAPM beta is correlated with volatility. Similarly, in column (3), we sort stocks on the estimated beta of their cash flows with respect to aggregate cash flows. Specifically, cash flow betas are computed via rolling twelve quarter regressions of quarter-on-quarter EBITDA growth on quarter-on-quarter national income growth. EBITDA is defined as the cumulative sum of operating income before depreciation. We require a minimum of $80 \%$ of observations in a window to compute a cash flow beta. If high volatility stocks have higher cash flow betas than low volatility stocks, then their valuations should fall more when aggregate growth expectations are low. In this case, our results in Table 2 could be explained by changes in aggregate growth expectations rather than change in the precautionary savings motive. Column (3) shows that the book-to-market based on cash flow betas is not significantly correlated with the real rate. Column (4) sort stocks based on CAPM betas that we compute using long-horizon returns. Specifically, long-run CAPM betas are computed using semi-annual returns over a rolling ten year window. The reference index is the CRSP Value-Weighted index and we require $80 \%$ of observations in order to compute a long-run CAPM beta. The idea here is that long-horizon returns are largely driven by cash flow news rather than discount rate news. Thus, long horizon CAPM betas can be viewed as another measure of cash flow beta. Column (4) indicates a positive relationship between the book-to-market spread based on long-run CAPM beta, but the relationship is not particularly strong in a statistical sense.

In column (5), we run a horse-race of all of these various book-to-market spreads against the Vol-BM spread. The main takeaway is that the Vol-BM spread drives out all other measures. In addition, the results in Tables 2 and 9 reveal that the Vol-BM spread delivers 
far and away the highest explanatory power for real rate variation, at least in terms of the regression $R^{2}$. In Table A.2 of the Online Appendix, we redo the entire analysis in quarteron-quarter changes instead of levels and come to the exact same conclusion - the relative valuation of high and low volatility stocks contains unique information about the real rate.

\section{Model}

This section presents a deliberately stylized model to rationalize the empirical findings. Idiosyncratic risk is priced in the model, because markets are segmented and investors are borrowing-constrained. Broadly interpreted, we think of the segmented markets assumption as representing households or professional investors who take concentrated bets in labor and financial markets. While we do not explicitly model why arbitrageurs do not arbitrage away pricing differentials, it is plausible that short-lived and risk-averse arbitrageurs would have limited arbitrage ability, especially for high-volatility stocks that typically have smaller market capitalization (Lee et al., 1991). Alternatively, Merton (1987) argues that agents' informational differences can drive segmentation in the stock market. Furthermore, segmented stock markets are also consistent with long-standing evidence of home or familiarity bias in individual stock holdings (see Barberis and Thaler (2003) for an overview), which may be either due to superior information or a preference for familiarity.

\subsection{Endowments and Preferences}

To capture the difference between high-volatility and low-volatility stocks, we assume that the economy consists of two Lucas trees, which are uncorrelated and differ only in terms of volatilities of the endowments. A share $p_{H}$ of stocks is of the high-volatility type and a share $p_{L}=1-p_{H}$ is low-volatility. We use lower case letters to denote logs. Both stocks' $\log$ dividends are distributed i.i.d. around a common trend to ensure that the shares of both 
stocks in the economy are stationary:

$$
\begin{aligned}
& c_{H, t}=\mu t+\varepsilon_{H, t}, \\
& c_{L, t}=\mu t+\varepsilon_{L, t}, \\
& {\left[\begin{array}{c}
\varepsilon_{L, t} \\
\varepsilon_{H, t}
\end{array}\right] \stackrel{i i d}{\sim} N\left(0,\left(\begin{array}{cc}
\sigma_{L}^{2} & 0 \\
0 & \sigma_{H}^{2}
\end{array}\right)\right) . }
\end{aligned}
$$

We assume that stock markets are segmented. Stock $i$ is priced by agent of type $i \in\{H, L\}$, who receives an endowment consumption stream equal to $c_{i, t}$. Assuming market segmentation helps us explain the empirical results, because it implies that investoremployees cannot diversify away idiosyncratic consumption risk, which hence generates a precautionary savings motive and is priced into the corresponding stock. In addition, we assume external habit formation preferences (Abel, 1990; Constantinides, 1990; Campbell and Cochrane, 1999; Menzly et al., 2004; Santos and Veronesi, 2010; Wachter, 2006; Lettau and Wachter, 2011). This model element is key to generating predictable stock returns, as documented in Section 3. Simultaneously, by generating time-varying curvature of the utility function, habit formation preferences also imply that the desire to hold the risk-free asset varies over time. This is the source of time-variation in the risk-free rate in our model. Agent $i$ maximizes the expected discounted sum of log consumption utility relative to habit $X_{i, t}$ :

$$
U_{i, t}=E_{t}\left[\sum_{\tau=t}^{\infty} \beta^{\tau} \log \left(C_{i, \tau}-X_{i, \tau}\right)\right], i=H, L
$$

We define type $i$ surplus consumption and inverse surplus consumption ratios:

$$
\begin{aligned}
S_{i, t} & =\frac{C_{i, t}-X_{i, t}}{C_{i, t}}, \\
G_{i, t} & =S_{i, t}^{-1} .
\end{aligned}
$$


We build on the tractable habit dynamics of Menzly et al. (2004), which generates closedform solutions for both the risk-free rate and equity premia, by assuming that inverse surplus consumption of agent $i$ follows a process of the form:

$$
G_{i, t+1}=\kappa \bar{G}+(1-\kappa) G_{i, t}-\alpha\left(G_{i, t}-\lambda\right) \varepsilon_{i, t+1}
$$

Habit dynamics are defined implicitly via (7) through (9). The advantage of specification

(9) is that it generates closed-form solutions for asset prices, while capturing the essence of Campbell and Cochrane (1999) habit formation. ${ }^{10}$

\subsection{Equity Markets}

Equities are priced by segmented investor clienteles, with investors of type $H$ trading the high-volatility stock and investors of type $L$ trading the low volatility stock. We obtain closed-form solutions for the price-dividend ratio of stock $i$ :

$$
\frac{P_{i, t}}{C_{i, t}}=a+b S_{i, t}
$$

for positive constants $a$ and $b$ that are given in Online Appendix A. Analogously to Campbell and Cochrane (1999), when agent $i$ 's consumption receives a negative shock that lowers consumption close to habit, surplus consumption $S_{i, t}$ is low. This raises the local coefficient of relative risk aversion $G_{i, t}$, driving up risk premia on the risky asset traded by agents of type $i$.

Finally, we define book-to-market ratios as simply as possible. We assume that a fixed fraction of assets are marked to market each year, so the book value represents an exponentiallyweighted moving average of past stock prices. The book-to-market ratio then is computed

\footnotetext{
${ }^{10}$ Santos and Veronesi (2010) show that if habit equals an exponentially-weighted moving average of past consumption as in Constantinides (1990) and Detemple and Zapatero (1991), this gives rise to dynamics of the form (9) with more complicated coefficients.
} 


$$
B M_{i, t}=\frac{B_{i, t}}{P_{i, t}}, B_{i, t}=(1-\rho) \sum_{\tau=1}^{\infty} \rho^{\tau} P_{i, t-\tau}
$$

\subsection{Bond Market}

Different investors potentially have different valuations for real risk-free one-period bonds, which are available in zero net supply. The real risk-free rate in the model is pinned down by assuming that agents are borrowing-constrained, so the risk-free rate is bid down to the minimum of investors' indifference points. The risk-free rate takes the tractable form:

$$
\begin{aligned}
r_{f, t}= & \min \left\{r_{f, H, t}, r_{f, L, t}\right\}, \\
r_{f, i, t}= & \mu-\log \beta-\frac{\sigma_{i}^{2}}{2}-\varepsilon_{i, t} \\
& -\log \left((1-\kappa)+\alpha \sigma_{i}^{2}+\left(\kappa \bar{G}-\sigma_{i}^{2} \alpha \lambda\right) G_{i, t}^{-1}\right), i \in\{H, L\} .
\end{aligned}
$$

The risk-free rate at which investor type $i$ is indifferent about investing in the bond market (14) can either increase or decrease with surplus consumption, depending on whether $\sigma_{i}^{2}$ is greater or smaller than the threshold $\frac{\kappa \bar{G}}{\lambda \alpha}$. If $\sigma_{i}^{2}>\frac{\kappa \bar{G}}{\lambda \alpha}$, the risk-free rate increases with surplus consumption. Intuitively, when surplus consumption is low, investors become more risk-averse over future endowment shocks, inducing them to save for a riskier future. As a result, the risk-free rate declines at the same time as surplus consumption. Alternatively, if $\sigma_{i}^{2}<\frac{\kappa \bar{G}}{\lambda \alpha}$, the risk-free rate is inversely related to surplus consumption. This case captures a consumer who faces only little uncertainty about his future consumption stream. Therefore, a decline in surplus consumption increases the marginal utility of consumption and the desire to borrow. Since volatility for this consumer is low, this effect is not offset by the consumer wanting to save for a riskier future. As a result, the investor wants to borrow, driving up the risk-free rate when surplus consumption is low. ${ }^{11}$

\footnotetext{
${ }^{11}$ The intuition is similar to a standard endowment economy with i.i.d. log consumption growth and power utility with risk aversion $\gamma$, where a decrease in surplus consumption $S_{t}$ acts similarly to an increase in risk
} 
We assume that for high-volatility investors, the time-varying precautionary savings effect dominates, while for low-volatility investors, the time-varying intertemporal substitution effect dominates. In addition, we assume that on average, the low-volatility type's time-varying intertemporal substitution effect balances the high-volatility type's desire for precautionary savings:

$$
p_{H} \sigma_{H}^{2}+p_{L} \sigma_{L}^{2}=\frac{\kappa \bar{G}}{\lambda \alpha}
$$

Since high-volatility investors have a stronger precautionary savings motive, they tend to value the risk-free bond more highly. Thus, they are typically the marginal investor in the bond market. In fact, unless low-volatility investors expect exceptionally low consumption growth from this period to the next, the risk-free asset is priced by high-volatility investors. ${ }^{12}$

\subsection{Calibration}

We calibrate the model to illustrate that the magnitudes of our empirical findings are within the range of reasonable values. Calibration parameters are reported in Table 10. Most parameters are set to standard values in the literature. We set the discount rate to 0.96, as in Menzly et al. (2004) and the consumption growth rate to 0.03 . We set $\lambda=10$, corresponding to an upper bound for the surplus consumption ratio of 0.1 as in Campbell and Cochrane (1999). The share of high-volatility stocks is $p_{H}=0.2$, corresponding to the top quintile of stocks by volatility in the empirical analysis. We set the standard deviations of consumption volatility to $\sigma_{H}=0.02$ and $\sigma_{L}=0.01$, so high-volatility stocks are subject to twice as much volatility as low-volatility stocks, matching the empirical ratio of return standard deviations of high-volatility and low-volatility portfolios. Conditional on these values, we pick the

aversion. In the standard endowment economy, the consumption Euler equation is $r_{f, t}=-\log \beta+\gamma \mu-\frac{\gamma^{2}}{2} \sigma^{2}$. If the endowment volatility $\sigma^{2}$ is sufficiently small, the risk-free rate moves positively with utility curvature $\gamma$. However, if the endowment volatility $\sigma^{2}$ is large, an increase in utility curvature increases the desire for precautionary savings and leads to a decrease in the risk-free rate.

${ }^{12}$ This follows from the observation that at $\varepsilon_{H, t}=\varepsilon_{L, t}=0$ we have that $r_{f, t}=r_{f, H, t}$ for any values $G_{H, t}, G_{L, t} \in\left[0, \lambda^{-1}\right]$. 
parameter $\alpha$, which determines the volatility of marginal utility, to match the empirical equity volatility of the aggregate stock market. Finally, we set the mean-reversion parameter $\kappa$ to a small value 0.01 to maximize the persistence of the log price-dividend ratio. We set the decay parameter for mark-to-market to 0.933, corresponding to a half-life of book assets of 10 years, or a depreciation rate of $7 \%$. Finally, we obtain the average inverse surplus consumption ratio from condition (15).

Table 11 shows simulated model moments from 1000 simulations of length 36 years, corresponding to our empirical sample size. Model and empirical moments are shown in bold if we cannot reject the null hypothesis that both are equal at the $95 \%$ level. The model matches the equity premium, equity volatility, and book-to-market ratio for the aggregate stock market. The aggregate book-to-market ratio is persistent, but less persistent than in the data, despite the low value for $\kappa$, a common problem in these types of habit formation models. ${ }^{13}$ The risk-free rate in the model is low and comparably volatile to the data.

The third panel in Table 11 shows that in the model the book-to-market ratios and excess returns of low-volatility stocks are lower than for high-volatility stocks. This might at first seem to contrast with the well-known idiosyncratic volatility puzzle (Ang et al., 2006b, 2009), which finds that low-volatility stocks have historically earned higher returns than high-volatility stocks. In our calibrated model, however, it would not be unusual to observe a positive return comparable to that in the data. In fact, $14.1 \%$ of our simulations generate low-minus-high volatility excess returns that are as large as the observed data. In addition, a wide range of additional explanations offered in the literature (Johnson, 2004; Fu, 2009; Stambaugh et al., 2015; Hou and Loh, 2016) may further contribute to the high average excess returns on low-volatility stocks.

The bottom panel of Table 11 shows that the model can generate the empirical relation

\footnotetext{
${ }^{13}$ Due to the convexity inherent in the analytically convenient Menzly et al. (2004) specification of inverse surplus consumption as a mean-reverting process, while stock market valuations are a function of surplus consumption, further decreases in the mean-reversion parameter $\kappa$ do not increase persistence of book-tomarket ratios. Instead, we face a tension in choosing the volatility of innovations to $G_{i, t}$, because more volatile innovations allow us to match the high volatility of equity returns, but also exacerbate the convex relation between equity valuations and $G_{i, t}$, thereby driving down the persistence of book-to-market ratios.
} 
between the risk-free rate and the cross section of equity valuations that we find in the data. Regressing the risk-free rate on the aggregate book-to-market ratio yields a small slope coefficient. But regressing the risk-free rate on the book-to-market spread between low- and high-volatility stocks yields a strong positive coefficient. In addition, the risk-free rate forecasts excess returns on the low-minus-high volatility equity portfolio with empirically reasonable magnitudes.

Intuitively, a decrease in high-volatility investors' surplus consumption makes these investors more risk averse, raising risk premia on high-volatility stocks relative to low-volatility stocks and driving down the low-minus-high volatility book-to-market ratio. At the same time, an increase in high-volatility investors' risk aversion increases their demand for precautionary savings and drives down the risk-free rate. This generates a positive relation between low-minus-high volatility book-to-market and the risk-free rate, as in the data. In the model, time-varying discount rates due to habit formation drive most of the variation in equity valuations, analogously to Campbell and Cochrane (1999), so book-to-market forecasts stock returns. Since the risk-free rate is related to the low-minus-high volatility book-to-market, it then also forecasts excess returns on the low-minus-high volatility portfolio. Finally, the aggregate book-to-market ratio is largely driven by low volatility investors, who represent the largest share of the market, while the risk-free rate is driven by the surplus consumption ratio of high-volatility investors, who tend to be the marginal risk-free bond investors. Thus, the model generates a low correlation between the aggregate book-to-market and the risk-free rate.

\section{$5 \quad$ Alternative Explanations}

The novel empirical results in Section 3 provide clear evidence of time-varying demand for precautionary savings as a significant determinant of time-varying real interest rates. We view the contribution of this paper as distinguishing between broad classes of real interest 
rate drivers without taking a stand on the exact channel that generates time-varying demand for precautionary savings. The main ingredients of any model that is consistent with our empirical findings are the following. First, idiosyncratic risk must give rise to a precautionary savings motive, so idiosyncratic risk must enter into investors' pricing kernel. Second, the pricing of idiosyncratic risk must vary over time. This can be achieved through habit formation as in Section 4, or through a time-varying distribution of heterogeneous investors as we discuss below. Third, the model must have at least two state variables. This is necessary to match the close relationship between the real rate and the Vol-BM spread, while maintaining no relationship between the real rate and aggregate book-to-market.

To give a sense of the range of explanations that could generate our empirical results, this section discusses alternative explanations for the empirical findings in addition to the model described in Section 4. First, we discuss how shifts in wealth between investors with different levels of risk aversion could generate time-varying precautionary savings motives. Second, we discuss a model, where consumers care about the volatility of individual goods in their consumption basket, thereby linking idiosyncratic stock returns to precautionary savings even in the absence of any market segmentation.

\subsection{Investors with Heterogeneous Risk Aversion}

While the model in Section 4 generates time-varying real rates from habit formation preferences, shifts in the wealth distribution towards agents who require a higher price of risk may act similarly on stocks and bonds (Yeung Lewis Chan (2002); Hall (2016); Barro and Mollerus (2014)). We view this channel as a complementary way of generating time-varying attitudes towards precautionary savings and within the same broad class of drivers for real rate variation as our model. Heterogeneity in risk aversion may arise either because agents have different preferences, or because agents' labor income is idiosyncratic, linking idiosyncratic stock return volatility with the quantity of background risk that individual agents are exposed to. Such a model would be able to match our main empirical result if a relative 
increase of wealth of investors with high risk aversion or high background risk increases the precautionary savings demand priced into the risk-free rate and the cross-section of stocks. At the same time, if different agents are marginal for the majority of stocks than for the risk-free asset, aggregate market valuations could be relatively unrelated to the risk-free rate, as in the data.

The literature on heterogenous agents has argued that risk-averse international investors are partly responsible for low interest rates (Caballero et al. (2008); Caballero and Krishnamurthy (2009)). To this end, we note that foreign ownership of Federal Treasury debt has increased fairly steadily since the 1970s. The Vol-BM spread, on the other hand, isolates a business-cycle frequency component, indicating that we measure a component of real rates that is different from increasing demand from abroad. Similarly, demographics tend to change more steadily than the component of precautionary savings that we isolate from the stock market.

\subsection{Good-Specific Preferences}

Idiosyncratic stock return volatility may be priced and informative about precautionary savings even in the absence of segmented markets, provided that consumers care about the volatility of individual goods in their consumption basket. To this end, we present and calibrate a representative agent model with good-specific preferences in Online Appendix C. Building on a long-standing marketing literature (e.g. Pollak (1970)), recent macro-finance research has studied the implications of good-specific habit preferences for asset prices and aggregate dynamics (Ravn et al. (2006); Heyerdahl-Larsen (2014); Gilchrist et al. (2015); Binsbergen (2016)). Following this literature, we assume that investors do not form habits over an aggregate consumption bundle, but instead get used to individual goods, such as cars, refrigerators, coffee, etc. In this setting, risk aversion over shocks to a volatile good can increase the motive for precautionary savings. When consumption of one good is low relative to habit, the corresponding stock price falls and the risk premium increases. Following an 
adverse shock to volatile goods' consumption, risk premia on high-volatility stocks relative to low-volatility stocks increase, depressing the low-minus-high volatility book-to-market. At the same time, investors' demand for precautionary savings increases to insure against future shocks to the volatile good, thereby depressing the real rate and generating positive co-movement between the real real and the low-minus-high volatility book-to-market.

\section{Conclusion}

This paper uses the cross-section of equity valuations to provide new empirical evidence for one broad driver of real interest rates: investors' time-varying demand for precautionary savings. Decomposing time-varying demand for precautionary savings into price of risk and quantity of risk, we find strong evidence of time-varying attitudes towards uncertainty, but little evidence of a link between the motive for precautionary savings and time-variation in uncertainty itself. A stylized model of segmented equity markets rationalizes these empirical findings as the result of time-varying risk-aversion of investors with highly volatile consumption streams. The goal of this paper is to distinguish between broad drivers of real interest

rates. Our results indicate that future research on models and drivers of precautionary savings is likely to be fruitful. 


\section{References}

Andrew B Abel. Asset Prices under Habit Formation and Catching up with the Joneses. The American Economic Review, pages 38-42, 1990.

Andrew Ang, Robert J Hodrick, Yuhang Xing, and Xiaoyan Zhang. The Cross-Section of Volatility and Expected Returns. The Journal of Finance, 61(1):259-299, 2006a.

Andrew Ang, Robert J Hodrick, Yuhang Xing, and Xiaoyan Zhang. The Cross-Section of Volatility and Expected Returns. The Journal of Finance, 61(1):259-299, 2006b.

Andrew Ang, Robert J Hodrick, Yuhang Xing, and Xiaoyan Zhang. High Idiosyncratic Volatility and Low Returns: International and Further US Evidence. Journal of Financial Economics, 91(1):1-23, 2009.

Malcolm Baker and Jeffrey Wurgler. Comovement and Predictability Relationships Between Bonds and the Cross-Section of Stocks. Review of Asset Pricing Studies, 2(1):57-87, 2012.

James Banks, Richard Blundell, and Agar Brugiavini. Risk pooling, Precautionary Saving and Consumption Growth. Review of Economic Studies, 68(4):757-779, 2001.

Nicholas Barberis and Richard Thaler. A survey of behavioral finance. Handbook of the Economics of Finance, 1:1053-1128, 2003.

Robert J Barro and Andrew Mollerus. Safe Assets. NBER Working Paper wp20652, 2014.

Shlomo Benartzi. Excessive Extrapolation and the Allocation of 401 (k) Accounts to Company Stock. The Journal of Finance, 56(5):1747-1764, 2001.

Ben S Bernanke and Kenneth N Kuttner. What Explains the Stock Market's Reaction to Federal Reserve Policy? Journal of Finance, 60(3):1221-1257, 2005.

Jules H Binsbergen. Good-specific habit formation and the cross-section of expected returns. The Journal of Finance, 2016.

Nicholas Bloom. The Impact of Uncertainty Shocks. Econometrica, 77:623-85, 2009.

Nicholas Bloom, Max Floetotto, Nir Jaimovich, Itay Saporta, and Stephen Terry. Really Uncertain Business Cycles. Working Paper, Stanford University, University College London, and Duke University, 2014.

Ricardo Caballero and Arvind Krishnamurthy. Global Imbalances and Financial Fragility. American Economic Review, 99(2):584-588, 2009.

Ricardo J Caballero, Emmanuel Farhi, and Pierre-Olivier Gourinchas. An Equilibrium Model of Global Imbalances and Low Interest Rates. American Economic Review, 98(1):358-93, 2008. 
John Y Campbell and John H Cochrane. By Force of Habit: A Consumption-Based Explanation of Aggregate Stock Market Behavior. Journal of Political Economy, 107(2): 205-251, 1999.

Christopher D Carroll and Andrew A Samwick. How Important is Precautionary Saving? Review of Economics and Statistics, 80(3):410-419, 1998.

John H Cochrane. Presidential Address: Discount Rates. The Journal of Finance, 66(4): 1047-1108, 2011.

John H. Cochrane. Macro-finance. Working Paper, Stanford University, July 2016.

George M Constantinides. Habit Formation: A Resolution of the Equity Premium Puzzle. Journal of Political Economy, pages 519-543, 1990.

Vasco Cúrdia, Andrea Ferrero, Ging Cee Ng, and Andrea Tambalotti. Has US Monetary Policy Tracked the Efficient Interest Rate? Journal of Monetary Economics, 70:72-83, 2015.

Jerome B Detemple and Fernando Zapatero. Asset Prices in an Exchange Economy. Econometrica, 59(6):1633-1657, 1991.

Ran Duchin, Thomas Gilbert, Jarrad Harford, and Christopher Hrdlicka. Precautionary Savings with Risky Assets: When Cash is not Cash. Journal of Finance, forthcoming, 2016.

Gauti B Eggertsson, Neil R Mehrotra, and Lawrence H Summers. Global Reserve Assets in a Low Interest Rate World Secular Stagnation in the Open Economy. American Economic Review, 106(5):503-507, 2016.

Eugene F Fama and Kenneth R French. Common risk factors in the returns on stocks and bonds. Journal of Financial Economics, 33(1):3-56, 1993.

Fangjian Fu. Idiosyncratic Risk and the Cross-Section of Expected Stock Returns. Journal of Financial Economics, 91(1):24-37, 2009.

Simon Gilchrist, Raphael Schoenle, Jae Sim, and Egon Zakrajsek. Inflation Dynamics During the Financial Crisis. Working Paper, Boston University, Brandeis University, Federal Reserve Board, 2015.

Robert J Gordon. Secular stagnation: A Supply-Side View. The American Economic Review, 105(5):54-59, 2015.

Robert E. Hall. Understanding the Decline in the Safe Real Interest Rate. NBER Working Paper, (22196), April 2016.

Lars Peter Hansen and Robert J Hodrick. Forward Exchange Rates as Optimal Predictors of Future Spot Rates: An Econometric Analysis. The Journal of Political Economy, pages 829-853, 1980. 
Samuel M Hartzmark. Economic Uncertainty and Interest Rates. Review of Asset Pricing Studies, 6(2):179-220, 2016.

Bernard Herskovic, Bryan Kelly, Hanno Lustig, and Stijn Van Nieuwerburgh. The Common Factor in Idiosyncratic Volatility: Quantitative Asset Pricing Implications. Journal of Financial Economics, 119(2):249-283, 2016.

Christian Heyerdahl-Larsen. Asset Prices and Real Exchange Rates with Deep Habits. Review of Financial Studies, 27(11):3280-3317, 2014.

Kathryn Holston, Thomas Laubach, and John Williams. Measuring the Natural Rate of Interest: International Trends and Determinants, 2016.

Kewei Hou and Roger K Loh. Have we Solved the Idiosyncratic Volatility Puzzle? Journal of Financial Economics, 121(1):167-194, 2016.

Timothy C Johnson. Forecast Dispersion and the Cross Section of Expected Returns. Journal of Finance, 59(5):1957-1978, 2004.

Thomas Laubach and John C Williams. Measuring the Natural Rate of Interest. Review of Economics and Statistics, 85(4):1063-1070, 2003.

Charles M C Lee, Andrei Shleifer, and Richard H Thaler. Investor Sentiment and the ClosedEnd Fund Puzzle. Journal of Finance, 46(1):75-109, 1991.

Martin Lettau and Jessica A Wachter. The Term Structures of Equity and Interest Rates. Journal of Financial Economics, 101(1):90-113, 2011.

Annamaria Lusardi. On the Importance of the Precautionary Saving Motive. American Economic Review, 88(2):449-453, 1998.

Alisdair McKay, Emi Nakamura, and Jón Steinsson. The Power of Forward Guidance Revisited. American Economic Review, 106(10):3133-3358, 2016.

Lior Menzly, Tano Santos, and Pietro Veronesi. Understanding Predictability. Journal of Political Economy, 112(1):1-47, 2004.

Robert C Merton. A simple model of capital market equilibrium with incomplete information. The Journal of Finance, 42(3):483-510, 1987.

Whitney K Newey and Kenneth D West. A Simple, Positive Semi-Definite, Heteroskedasticity and Autocorrelation Consistent Covariance Matrix. Econometrica, 55(3):703-708, 1987.

Jonathan A Parker and Bruce Preston. Precautionary Saving and Consumption Fluctuations. American Economic Review, 95(4):1119-1143, 2005.

Robert A Pollak. Habit Formation and Dynamic Demand Functions. Journal of Political Economy, 78(4):745-763, 1970. 
Morten Ravn, Stephanie Schmitt-Grohé, and Martin Uribe. Deep Habits. The Review of Economic Studies, 73(1):195-218, 2006.

Leigh A Riddick and Toni M Whited. The corporate propensity to save. Journal of Finance, 64(4):1729-1766, 2009.

Christina D Romer and David H Romer. A New Measure of Monetary Shocks: Derivation and Implications. American Economic Review, 94(4):1055-1084, 2004.

Tano Santos and Pietro Veronesi. Habit formation, the Cross Section of Stock Returns and the Cash-Flow Risk Puzzle. Journal of Financial Economics, 98(2):385-413, 2010.

Robert F Stambaugh, Jianfeng Yu, and Yu Yuan. Arbitrage Asymmetry and the Idiosyncratic Volatility Puzzle. Journal of Finance, 70(5):1903-1948, 2015.

Lawrence H Summers. Demand Side Secular Stagnation. American Economic Review, 105 (5):60-65, 2015.

Jessica A Wachter. A Consumption-Based Model of the Term Structure of Interest Rates. Journal of Financial Economics, 79(2):365-399, 2006.

Michael Weber. Cash Flow Duration and the Term Structure of Equity Returns. Working Paper, University of Chicago, 2016.

Leonid Kogan Yeung Lewis Chan. Catching Up with the Joneses: Heterogeneous Preferences and the Dynamics of Asset Prices. Journal of Political Economy, 110(6):1255-1285, 2002. 


\section{FIGURES}

Figure 1: Book-to-Market Spread Between Low- and High-Volatility Stocks

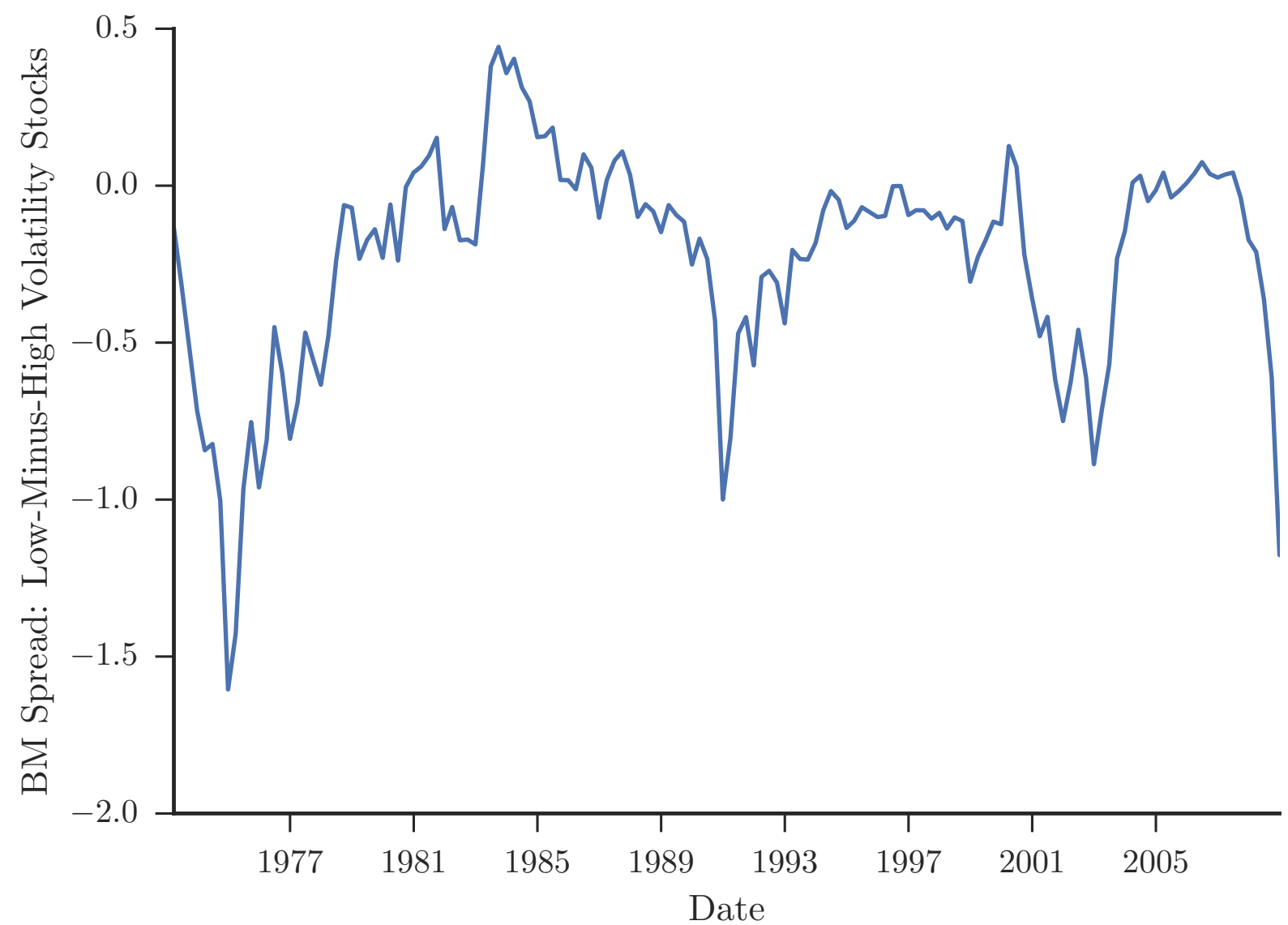

Notes: This figure plots the spread in book-to-market ratios between low and high idiosyncratic volatility stocks. Idiosyncratic volatility is defined as the residual volatility of returns after controlling for exposure to the Fama and French (1993) factors. For all NYSE, AMEX, and NASDAQ firms in CRSP, we compute idiosyncratic volatility at the end of each quarter using the previous sixty days of daily returns. We then form equal-weighted portfolios based on the quintiles of idiosyncratic volatility. Within each quintile, we compute the average book-to-market (BM) ratio. The Data Appendix contains full details on how we compute BM ratios. The plotted series is the difference in average book-to-market ratios between the low volatility and high volatility portfolios. Data is quarterly and spans 1973Q1-2008Q4. 


\section{Figure 2: One-Year Real Rate: Actual and Fitted Value}

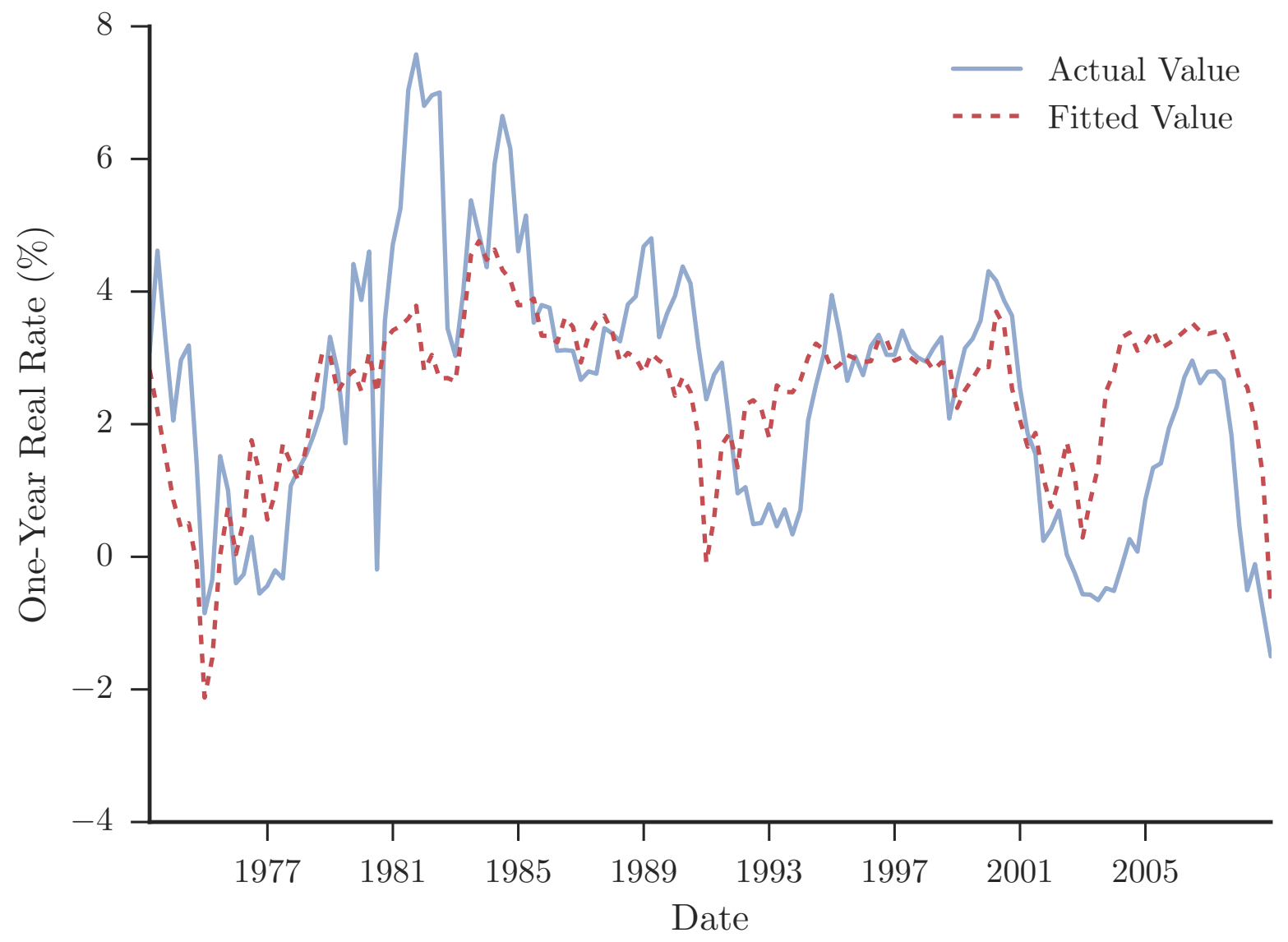

Notes: This figure plots the one-year real rate and the fitted value from a regression of the real rate on the spread in book-tomarket ratios between low and high idiosyncratic volatility stocks. Idiosyncratic volatility is defined as the residual volatility of returns after controlling for exposure to the Fama and French (1993) factors. For all NYSE, AMEX, and NASDAQ firms in CRSP, we compute idiosyncratic volatility at the end of each quarter using the previous sixty days of daily returns. We then form equal-weighted portfolios based on the quintiles of idiosyncratic volatility. Within each quintile, we compute the average book-to-market (BM) ratio. The Data Appendix contains full details on how we compute BM ratios. The one-year real rate is the one-year Treasury bill rate net of one-year survey expectations of the inflation (the GDP deflator) from the Survey of Professional Forecasters. Data is quarterly and spans 1973Q1-2008Q4. 
Figure 3: Scatterplot of One-Year Real Rate against the Vol-BM Spread

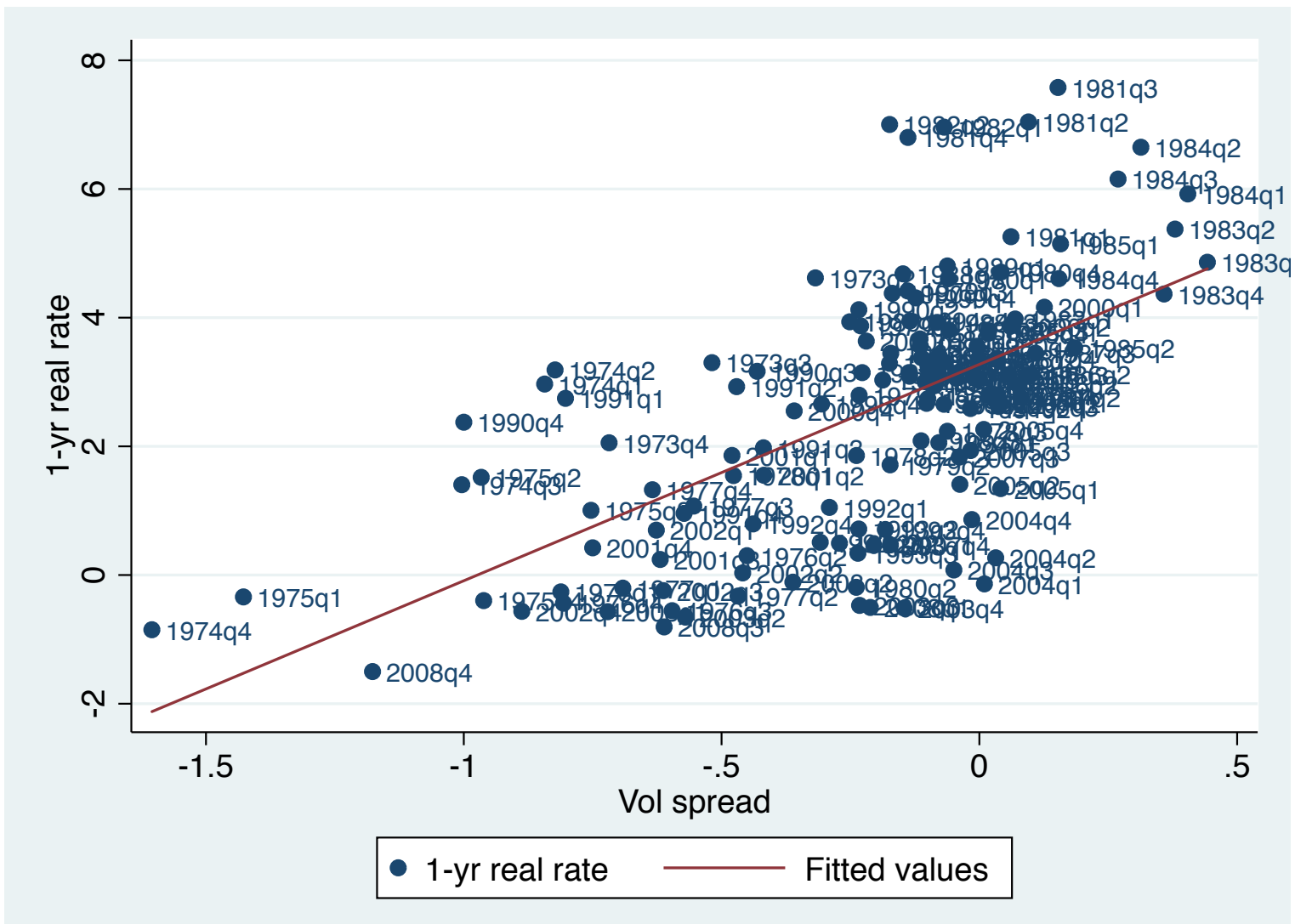

Notes: This figure plots the one-year real interest rate against the spread in book-to-market ratios between low and high idiosyncratic volatility stocks. Idiosyncratic volatility is defined as the residual volatility of returns after controlling for exposure to the Fama and French (1993) factors. For all NYSE, AMEX, and NASDAQ firms in CRSP, we compute idiosyncratic volatility at the end of each quarter using the previous sixty days of daily returns. We then form equal-weighted portfolios based on the quintiles of idiosyncratic volatility. Within each quintile, we compute the average book-to-market (BM) ratio. The Data Appendix contains full details on how we compute BM ratios. The one-year real rate is the one-year Treasury bill rate net of one-year survey expectations of the inflation (the GDP deflator) from the Survey of Professional Forecasters. Data is quarterly and spans 1973Q1-2008Q4. 


\section{TABLES}

Table 1: Summary Statistics for Volatility-Sorted Portfolios

Panel A: Book-to-Market Ratios

\begin{tabular}{lcccccc}
\hline & High-Vol & 4 & 3 & 2 & Low-Vol & Low-High \\
\hline Mean & 1.11 & 0.91 & 0.86 & 0.85 & 0.87 & -0.23 \\
Volatility & 0.49 & 0.36 & 0.30 & 0.26 & 0.26 & 0.35 \\
Min & 0.48 & 0.49 & 0.49 & 0.51 & 0.52 & -1.60 \\
Median & 0.92 & 0.80 & 0.78 & 0.76 & 0.82 & -0.13 \\
Max & 3.15 & 2.27 & 1.87 & 1.68 & 1.55 & 0.44 \\
\hline
\end{tabular}

Panel B: Realized Excess Returns

\begin{tabular}{lcccccc}
\hline & High-Vol & 4 & 3 & 2 & Low-Vol & Low-High \\
\hline Mean & 6.48 & 8.13 & 10.22 & 9.49 & 7.80 & 1.32 \\
Volatility & 38.70 & 30.97 & 24.91 & 19.84 & 15.25 & 29.75 \\
Median & 0.68 & 7.18 & 11.05 & 10.11 & 9.35 & 8.80 \\
Min & -41.07 & -36.70 & -31.44 & -28.57 & -21.67 & -52.44 \\
Max & 76.44 & 57.62 & 42.56 & 35.01 & 24.00 & 46.86 \\
$\alpha$ & -5.29 & -1.23 & 1.96 & 1.38 & 0.89 & 6.18 \\
$t(\alpha)$ & -1.66 & -0.80 & 2.30 & 1.40 & 0.69 & 1.63 \\
CAPM- $\beta$ & 1.22 & 1.15 & 1.02 & 0.94 & 0.79 & -0.42 \\
SMB- $\beta$ & 1.85 & 1.38 & 1.02 & 0.61 & 0.28 & -1.57 \\
HML- $\beta$ & 0.28 & 0.11 & 0.17 & 0.37 & 0.42 & 0.14 \\
\hline
\end{tabular}

Notes: This table presents summary statistics for portfolios formed on idiosyncratic volatility. Idiosyncratic volatility is defined as the residual volatility of returns after controlling for exposure to the Fama and French (1993) factors. For all NYSE, AMEX, and NASDAQ firms in CRSP, we compute idiosyncratic volatility at the end of each quarter using the previous sixty days of daily returns. We then form equal-weighted portfolios based on the quintiles of idiosyncratic volatility. Panel A shows summary statistics on the average book-to-market (BM) ratio within each quintile. The Data Appendix contains full details on how we form portfolios and compute book-to-market ratios. Panel B displays summary statistics on the realized excess returns of each quintile (in percentage terms). The $\alpha$ is the (annualized) intercept from a regression of excess returns on the Fama and French (1993) factors. Standard errors are computed via GMM by pooling all portfolios. We allow for withinportfolio heteroskedasticity and cross-portfolio correlations. The mean, volatility, and median returns are all annualized. Data is quarterly and runs from 1973Q1 to 2008Q4. The riskless rate for computing excess returns and quarterly returns on the Fama and French (1993) factors are aggregated using monthly data from Ken French's website. 
Table 2: What Explains Real Rate Variation (Level Regression)?

Dependent Variable: One-Year Real Rate

(1)

Vol-BM Spread

$3.36^{* *}$

$3.78^{* *}$

Aggregate BM

$2.58^{* *}$

$\mathbb{E}$ [GDP Growth]

\begin{tabular}{lccc} 
Constant & $3.27^{* *}$ & 1.22 & $2.55^{* *}$ \\
& $(6.96)$ & $(0.96)$ & $(2.74)$ \\
\hline Adj. $R^{2}$ & 0.369 & 0.057 & 0.513 \\
$N$ & 144 & 144 & 144 \\
\hline
\end{tabular}

Notes: This table reports regression estimates of the one-year real rate on the spread in book-to-market (BM) ratios between high idiosyncratic volatility and low idiosyncratic volatility stocks (Vol-BM Spread). Idiosyncratic volatility is defined as the residual volatility of returns after controlling for exposure to the Fama and French (1993) factors. For all NYSE, AMEX, and NASDAQ firms in CRSP, we compute idiosyncratic volatility at the end of each quarter using the previous sixty days of daily returns. We then form equal-weighted portfolios based on the quintiles of idiosyncratic volatility. Within each quintile, we compute the average book-to-market (BM) ratio. The Data Appendix contains full details on how we compute BM ratios. Vol-BM Spread is defined as the difference in BM ratios between the bottom and top quintile portfolios. Aggregate BM is computed by summing book equity values across all firms and divided by the corresponding sum of market equity values. $\mathbb{E}[$ GDP Growth] is expected GDP growth from the Survey of Professional Forecasters. The one-year real rate is the one-year Treasury bill rate net of one-year survey expectations of the inflation (the GDP deflator) from the Survey of Professional Forecasters. Standard errors are computed using both Newey-West (1987) and Hansen-Hodrick (1980) with twelve lags, and we report the more conservative $t$-statistic of the two. * indicates a p-value of less than 0.1 and $* *$ indicates a p-value of less than 0.05. Data is quarterly and spans 1973Q1-2008Q4. 
Table 3: What Explains Real Rate Variation (First-Differenced Regression)?

\begin{tabular}{lccccccc}
\hline Dependent Variable: & \multicolumn{2}{c}{ 1-Qtr $\Delta$ Real Rate } & & \multicolumn{3}{c}{ 4-Qtr $\Delta$ Real Rate } \\
\cline { 2 - 3 } \cline { 6 - 7 } & $(1)$ & $(2)$ & $(3)$ & & $(4)$ & $(5)$ & $(6)$ \\
\hline$\Delta$ Vol BM Spread & $2.44^{* *}$ & & $1.96^{* *}$ & & $2.45^{* *}$ & & $3.52^{* *}$ \\
& $(3.87)$ & & $(3.66)$ & & $(4.40)$ & & $(5.56)$ \\
& & & & & & & \\
$\Delta$ Agg. BM Ratio & & $-5.43^{* *}$ & 1.27 & & -2.49 & 3.06 \\
& & $(-2.30)$ & $(0.51)$ & & $(-1.04)$ & $(1.41)$ \\
& & & & & & \\
$\Delta \mathbb{E}[$ GDP Growth] & & & 0.22 & & & -0.17 \\
& & & $(1.21)$ & & & $(-0.96)$ \\
Constant & -0.01 & -0.03 & -0.01 & & -0.10 & -0.12 & -0.10 \\
& $(-0.24)$ & $(-0.45)$ & $(-0.15)$ & $(-0.50)$ & $(-0.49)$ & $(-0.49)$ \\
\hline Adj. $R^{2}$ & 0.163 & 0.043 & 0.170 & & 0.199 & 0.016 & 0.234 \\
$N$ & 143 & 143 & 143 & & 140 & 140 & 140 \\
\hline
\end{tabular}

Notes: This table reports regression estimates of the one-year real rate on the spread in book-to-market (BM) ratios between high idiosyncratic volatility and low idiosyncratic volatility stocks (Vol-BM Spread). Idiosyncratic volatility is defined as the residual volatility of returns after controlling for exposure to the Fama and French (1993) factors. For all NYSE, AMEX, and NASDAQ firms in CRSP, we compute idiosyncratic volatility at the end of each quarter using the previous sixty days of daily returns. We then form equal-weighted portfolios based on the quintiles of idiosyncratic volatility. Within each quintile, we compute the average book-to-market (BM) ratio. The Data Appendix contains full details on how we compute BM ratios. VolBM Spread is defined as the difference in BM ratios between the bottom and top quintile portfolios. Aggregate BM is computed by summing book equity values across all firms and divided by the corresponding sum of market equity values. $\mathbb{E}$ [GDP Growth] is expected GDP growth from the Survey of Professional Forecasters. The one-year real rate is the one-year Treasury bill rate net of one-year survey expectations of the inflation (the GDP deflator) from the Survey of Professional Forecasters. Columns (1)-(3) run the regression in first differences (i.e. one-quarter changes). Columns (4)-(6) run the regression in quarter-on-quarter differences (i.e. four-quarter changes). Standard errors are computed using both Newey-West (1987) and Hansen-Hodrick (1980) with six lags, and we report the more conservative t-statistic of the two. * indicates a p-value of less than 0.1 and $* *$ indicates a p-value of less than 0.05. Data is quarterly and spans 1973Q2-2008Q4. 


\section{Table 4: Forecasting Returns of Portfolios Sorted on Volatility}

\begin{tabular}{lcccc}
\hline Panel A - Quarterly Forecasting & \multicolumn{3}{c}{ Returns $_{t \rightarrow t+1}$} \\
& $(1)$ & $(2)$ & $(3)$ & $(4)$ \\
\hline Vol-BM Spread $_{t}$ & $15.27^{* *}$ & $7.53^{* *}$ & & \\
& $(4.82)$ & $(3.35)$ & & \\
& & & & \\
Real Rate & & & $2.02^{* *}$ & 0.69 \\
& & & $(2.94)$ & $(1.53)$ \\
& & & $-4.80^{* *}$ & -0.08 \\
Constant & $3.71^{* *}$ & $3.28^{* *}$ & $(-2.15)$ & $(-0.05)$ \\
& $(3.22)$ & $(3.71)$ & $\mathrm{N}$ & $\mathrm{Y}$ \\
Fama-French & $\mathrm{N}$ & $\mathrm{Y}$ & 0.561 \\
Adj. $R^{2}$ & 0.116 & 0.581 & 143 & 143 \\
$N$ & 143 & 143 & & \\
\hline
\end{tabular}

Panel B - Annual Forecasting

\section{Returns $_{t \rightarrow t+4}$}

$(2)$

(3)

\begin{tabular}{lcccc}
\hline Vol-BM Spread $_{t}$ & $51.21^{* *}$ & $36.46^{* *}$ & & \\
& $(3.37)$ & $(2.11)$ & & \\
& & & & \\
Real Rate & & & $(2.88)$ & $(1.47)$ \\
& & & & \\
& & & $-15.83^{* *}$ & -6.71 \\
Constant & $11.06^{* *}$ & 8.65 & $(-2.13)$ & $(-0.98)$ \\
\hline Fama-French & $(2.44)$ & $(1.55)$ & $\mathrm{N}$ & $\mathrm{Y}$ \\
Adj. $R^{2}$ & $\mathrm{~N}$ & $\mathrm{Y}$ & 0.150 & 0.566 \\
$N$ & 0.378 & 0.679 & 140 & 140 \\
\hline
\end{tabular}

Notes: This table reports forecasting regressions of portfolios formed on idiosyncratic volatility. Idiosyncratic volatility is defined as the residual volatility of returns after controlling for exposure to the Fama and French (1993) factors. For all NYSE, AMEX, and NASDAQ firms in CRSP, we compute idiosyncratic volatility at the end of each quarter using the previous sixty days of daily returns. We then form equal-weighted portfolios based on the quintiles of idiosyncratic volatility. Within each quintile, we compute the average book-to-market (BM) ratio. The Data Appendix contains full details on how we compute BM ratios. Vol-BM Spread is defined as the difference in BM ratios between the bottom and top quintile portfolios. Returns in the forecasting regression correspond to the low-minus-high IVOL portfolio. The real rate is the one-year Treasury bill rate net of one-year survey expectations of the inflation (the GDP deflator) from the Survey of Professional Forecasters. Columns (2) and (4) include the three Fama-French factors as controls. For quarterly regressions, standard errors are computed using both Newey-West (1987) and Hansen-Hodrick (1980) with five lags, and we report the more conservative t-statistic of the two. For annual horizons we use Hodrick (1992) standard errors. * indicates a p-value of less than 0.1 and $* *$ indicates a p-value of less than 0.05. Data is quarterly and spans 1973Q2-2008Q4. Returns are in percentage points. 
Table 5: Forecasting Annual Returns of the Fama-French Factors

\begin{tabular}{|c|c|c|c|c|c|c|}
\hline & \multicolumn{2}{|c|}{ Mkt-Rf $f_{t \rightarrow t+4}$} & \multicolumn{2}{|c|}{$\mathrm{SMB}_{t \rightarrow t+4}$} & \multicolumn{2}{|c|}{$\mathrm{HML}_{t \rightarrow t+4}$} \\
\hline & (1) & (2) & (3) & (4) & (5) & $(6)$ \\
\hline Vol-BM Spread $_{t}$ & $\begin{array}{c}-3.72 \\
(-0.39)\end{array}$ & & $\begin{array}{c}-14.86^{* *} \\
(-3.01)\end{array}$ & & $\begin{array}{c}0.89 \\
(0.17)\end{array}$ & \\
\hline Real Rate $_{t}$ & & $\begin{array}{c}0.09 \\
(0.07)\end{array}$ & & $\begin{array}{c}-2.17^{* *} \\
(-3.14)\end{array}$ & & $\begin{array}{c}0.20 \\
(0.23)\end{array}$ \\
\hline Constant & $\begin{array}{l}5.27^{*} \\
(1.70)\end{array}$ & $\begin{array}{c}5.85 \\
(1.39)\end{array}$ & $\begin{array}{c}-0.38 \\
(-0.23)\end{array}$ & $\begin{array}{c}8.52^{* *} \\
(3.47)\end{array}$ & $\begin{array}{c}6.20^{* *} \\
(2.72)\end{array}$ & $\begin{array}{l}5.49^{* *} \\
(2.16)\end{array}$ \\
\hline Adj. $R^{2}$ & -0.00 & -0.01 & 0.21 & 0.13 & -0.01 & -0.01 \\
\hline$N$ & 140 & 140 & 140 & 140 & 140 & 140 \\
\hline
\end{tabular}

Notes: This table reports forecasting regressions of annual returns on the Fama and French (1993) factors. VOL-BM Spread is the spread in book-to-market ratios between stocks with low and high idiosyncratic volatility. Idiosyncratic volatility is defined as the residual volatility of returns after controlling for exposure to the Fama and French (1993) factors. For all NYSE, AMEX, and NASDAQ firms in CRSP, we compute idiosyncratic volatility at the end of each quarter using the previous sixty days of daily returns. We then form equal-weighted portfolios based on the quintiles of idiosyncratic volatility. Within each quintile, we compute the average book-to-market (BM) ratio. The Data Appendix contains full details on how we compute BM ratios. The real rate is the one-year Treasury bill rate net of one-year survey expectations of the inflation (the GDP deflator) from the Survey of Professional Forecasters. Standard errors are computed according to Hodrick (1992). * indicates a p-value of 0.1 and ** indicates a p-value of 0.05. Data is quarterly and spans 1973Q2-2008Q4. Returns are in percentage points. 
Table 6: Contemporaneous Real Rate Variation and the Quantity of Risk

\begin{tabular}{|c|c|c|c|c|c|c|}
\hline \multirow[t]{2}{*}{ Dependent Variable: } & \multicolumn{3}{|c|}{ Real Rate (Level) } & \multicolumn{3}{|c|}{ 4-Q $\Delta$ Real Rate } \\
\hline & (1) & $(2)$ & $(3)$ & (4) & $(5)$ & (6) \\
\hline \multirow[t]{2}{*}{$\sigma(\mathrm{LMH}-\mathrm{Vol}$ Portfolio $)$} & 0.02 & & -0.001 & $0.03^{* *}$ & & 0.001 \\
\hline & $(1.15)$ & & $(-0.07)$ & $(3.10)$ & & $(0.06)$ \\
\hline \multirow[t]{2}{*}{$\sigma($ TFP Growth $)$} & & 0.63 & $0.80^{* *}$ & & -0.37 & -0.05 \\
\hline & & $(1.26)$ & $(2.60)$ & & $(-1.39)$ & $(-0.23)$ \\
\hline \multirow[t]{2}{*}{$\sigma(\mathrm{Mkt}-\mathrm{Rf})$} & & $-0.21^{* *}$ & -0.05 & & $-0.11^{* *}$ & -0.05 \\
\hline & & $(-3.36)$ & $(-1.43)$ & & $(-2.57)$ & $(-1.33)$ \\
\hline \multirow[t]{2}{*}{$\sigma(\mathrm{SMB})$} & & $0.30 * *$ & 0.08 & & $0.11^{* *}$ & 0.03 \\
\hline & & $(4.05)$ & $(1.32)$ & & $(2.90)$ & $(0.92)$ \\
\hline \multirow[t]{2}{*}{$\sigma(\mathrm{HML})$} & & 0.10 & 0.06 & & 0.08 & 0.07 \\
\hline & & $(0.98)$ & $(0.82)$ & & $(0.97)$ & $(0.98)$ \\
\hline \multirow[t]{2}{*}{ Vol-BM Spread } & & & $3.57^{* *}$ & & & $2.18^{* *}$ \\
\hline & & & $(6.77)$ & & & $(2.79)$ \\
\hline $\operatorname{Adj} R^{2}$ & 0.049 & 0.194 & 0.484 & 0.059 & 0.090 & 0.192 \\
\hline$N$ & 144 & 144 & 144 & 140 & 140 & 140 \\
\hline
\end{tabular}

Notes: This table reports regression estimates of the one-year real rate on various measures of risk. $\sigma$ (TFP Growth) is the volatility of TFP growth that is implied by a GARCH model (see Table A1 of the Online Appendix). $\sigma$ (Mkt-Rf), $\sigma$ (SMB), and $\sigma$ (HML) are the within-quarter volatility of the three Fama and French (1993) factors, which we compute using daily data. Vol-BM spread is the difference in book-to-market ratios between high idiosyncratic volatility and low idiosyncratic volatility stocks. Idiosyncratic volatility is defined as the residual volatility of returns after controlling for exposure to the Fama and French (1993) factors. For all NYSE, AMEX, and NASDAQ firms in CRSP, we compute idiosyncratic volatility at the end of each quarter using the previous sixty days of daily returns. We then form equal-weighted portfolios based on the quintiles of idiosyncratic volatility. Within each quintile, we compute the average book-to-market (BM) ratio. The Data Appendix contains full details on how we compute BM ratios. $\sigma$ (LMH-Vol Portfolio) is the difference in the average realized return volatility for stocks in the low volatility portfolio minus the average realized volatility in the high volatility portfolio, which we compute using daily data. The real rate is the one-year Treasury bill rate net of one-year survey expectations of the inflation (the GDP deflator) from the Survey of Professional Forecasters. Columns (1)-(3) run the regression in levels. Columns (4)-(6) run the regression in quarter-on-quarter differences (i.e. four-quarter changes). Standard errors are computed using both Newey-West (1987) and Hansen-Hodrick (1980) with twelve lags for level regressions and six lags for the regression using Q-on-Q changes. We report the more conservative t-statistic of the two. * indicates a p-value of less than 0.1 and $* *$ indicates a p-value of less than 0.05. All regressions have a constant, but we omit the estimates to save space. Data is quarterly and spans 1973Q2-2008Q4. 
Table 7: Forecasting Returns of Volatility-Sorted Portfolios with the Quantity of Risk

\begin{tabular}{|c|c|c|c|c|c|c|c|}
\hline \multirow[t]{2}{*}{ Dependent Variable: } & \multicolumn{7}{|c|}{ Returns $_{t \rightarrow t+4}$} \\
\hline & $(1)$ & $(2)$ & $(3)$ & $(4)$ & $(5)$ & $(6)$ & $(7)$ \\
\hline \multirow[t]{2}{*}{ Real Rate $_{t}$} & & $5.66^{* *}$ & $6.70^{* *}$ & $5.83^{* *}$ & $5.96^{* *}$ & $6.19^{* *}$ & $3.78^{*}$ \\
\hline & & $(2.47)$ & $(2.87)$ & $(2.87)$ & $(2.90)$ & $(2.97)$ & $(1.78)$ \\
\hline \multirow[t]{2}{*}{$\sigma$ (LMH-Vol Portfolio) } & 0.20 & 0.11 & & & & & $0.27^{*}$ \\
\hline & $(1.24)$ & $(0.63)$ & & & & & $(1.77)$ \\
\hline \multirow[t]{2}{*}{$\sigma_{t}$ (TFP Growth) } & & & -6.37 & & & & -5.03 \\
\hline & & & $(-1.06)$ & & & & $(-0.89)$ \\
\hline \multirow[t]{2}{*}{$\sigma_{t}(\mathrm{Mkt}-\mathrm{Rf})$} & & & & -0.79 & & & $-3.46^{* *}$ \\
\hline & & & & $(-1.14)$ & & & $(-2.35)$ \\
\hline \multirow[t]{2}{*}{$\sigma_{t}(\mathrm{SMB})$} & & & & & 0.43 & & $4.74^{* *}$ \\
\hline & & & & & $(0.32)$ & & $(2.21)$ \\
\hline \multirow[t]{2}{*}{$\sigma_{t}(\mathrm{HML})$} & & & & & & -0.68 & 1.52 \\
\hline & & & & & & $(-0.39)$ & $(0.72)$ \\
\hline \multirow[t]{2}{*}{ Constant } & 13.47 & -7.58 & 2.60 & -4.43 & $-19.02^{*}$ & -11.96 & 25.83 \\
\hline & $(1.33)$ & $(-0.53)$ & $(0.15)$ & $(-0.46)$ & $(-1.64)$ & $(-1.09)$ & $(1.29)$ \\
\hline Adj. $R^{2}$ & 0.03 & 0.15 & 0.18 & 0.17 & 0.15 & 0.15 & 0.32 \\
\hline$N$ & 140 & 140 & 140 & 140 & 140 & 140 & 140 \\
\hline
\end{tabular}

Notes: This table reports annual return forecasting regressions of portfolios formed on idiosyncratic volatility. Idiosyncratic volatility is defined as the residual volatility of returns after controlling for exposure to the Fama and French (1993) factors. For all NYSE, AMEX, and NASDAQ firms in CRSP, we compute idiosyncratic volatility at the end of each quarter using the previous sixty days of daily returns. We then form equal-weighted portfolios based on the quintiles of idiosyncratic volatility. Returns in the forecasting regression correspond to the low-minus-high IVOL portfolio. $\sigma$ (LMH-Vol Portfolio) is the difference in the average realized return volatility for stocks in the low volatility portfolio minus the average realized volatility in the high volatility portfolio, which we compute using daily data. $\sigma$ (TFP Growth) is the volatility of TFP growth that is implied by a GARCH model (see Table A1 of the Online Appendix). $\sigma$ (Mkt-Rf), $\sigma$ (SMB), and $\sigma$ (HML) are the within-quarter volatility of the three Fama and French (1993) factors, which we compute using daily data. The real rate is the one-year Treasury bill rate net of one-year survey expectations of the inflation (the GDP deflator) from the Survey of Professional Forecasters. Column (2) includes the three Fama-French factors as controls. Standard errors are computed according to Hodrick (1992). * indicates a p-value of less than 0.1 and ** indicates a p-value of less than 0.05. Data is quarterly and spans 1973Q2-2008Q4. Returns are in percentage points. 
Table 8: Forecasting Realized Volatility

Panel A: Forecasting Volatility Using the Vol-BM Spread

\begin{tabular}{|c|c|c|c|c|c|}
\hline \multirow[t]{3}{*}{ Dependent Variable: } & \multicolumn{5}{|c|}{ Realized Volatility $_{t \rightarrow t+1}$} \\
\hline & LMH-Vol & TFP & MktRf & SMB & HML \\
\hline & (1) & $(2)$ & (3) & $(4)$ & $(5)$ \\
\hline \multirow[t]{2}{*}{ Vol-BM Spread $_{t}$} & 14.73 & -0.63 & -3.87 & 0.73 & -0.52 \\
\hline & $(0.75)$ & $(-0.98)$ & $(-1.37)$ & $(0.55)$ & $(-0.34)$ \\
\hline \multirow[t]{2}{*}{ Constant } & $-66.89 * *$ & $3.03^{* *}$ & $13.65^{* *}$ & $8.16^{* *}$ & $6.57^{* *}$ \\
\hline & $(-6.39)$ & $(8.33)$ & $(12.27)$ & $(11.59)$ & $(8.83)$ \\
\hline Adj. $R^{2}$ & 0.03 & 0.05 & 0.02 & -0.00 & -0.01 \\
\hline$N$ & 143 & 143 & 143 & 143 & 143 \\
\hline
\end{tabular}

Panel B: Forecasting Volatility Using the Real Rate

\begin{tabular}{|c|c|c|c|c|c|}
\hline \multirow[t]{3}{*}{ Dependent Variable: } & \multicolumn{5}{|c|}{ Realized Volatility $_{t \rightarrow t+1}$} \\
\hline & LMH-Vol & TFP & MktRf & SMB & HML \\
\hline & (1) & $(2)$ & $(3)$ & $(4)$ & $(5)$ \\
\hline \multirow[t]{2}{*}{${\text { Real } \text { Rate }_{t}}$} & 2.80 & 0.09 & -0.42 & 0.08 & 0.09 \\
\hline & $(1.05)$ & $(0.83)$ & $(-0.69)$ & $(0.29)$ & $(0.28)$ \\
\hline \multirow[t]{2}{*}{ Constant } & $-77.26^{* *}$ & $2.95^{* *}$ & $15.58^{* *}$ & $7.80^{* *}$ & $6.46^{* *}$ \\
\hline & $(-6.17)$ & $(9.80)$ & $(6.33)$ & $(6.33)$ & $(5.66)$ \\
\hline Adj. $R^{2}$ & 0.03 & 0.03 & 0.00 & -0.00 & -0.00 \\
\hline$N$ & 143 & 143 & 143 & 143 & 143 \\
\hline
\end{tabular}

Notes: This table reports forecasting regressions of realized volatility. TFP volatility is the volatility of TFP growth that is implied by a GARCH model (see Table A1 of the Online Appendix). MktRf Vol, SMB Vol, and HML Vol are the within-quarter volatility of the three Fama and French (1993) factors, which we compute using daily data. Vol-BM Spread is the difference in book-to-market ratios between high idiosyncratic volatility and low idiosyncratic volatility stocks. Idiosyncratic volatility is defined as the residual volatility of returns after controlling for exposure to the Fama and French (1993) factors. For all NYSE, AMEX, and NASDAQ firms in CRSP, we compute idiosyncratic volatility at the end of each quarter using the previous sixty days of daily returns. We then form equal-weighted portfolios based on the quintiles of idiosyncratic volatility. Within each quintile, we compute the average book-to-market (BM) ratio. The Data Appendix contains full details on how we compute BM ratios. $\mathrm{LMH}-\mathrm{Vol}$ is the difference in the average realized return volatility between the low and high idiosyncratic portfolios, which we compute using daily data. The real rate is the one-year Treasury bill rate net of one-year survey expectations of the inflation (the GDP deflator) from the Survey of Professional Forecasters. Standard errors are computed using both Newey-West (1987) and Hansen-Hodrick (1980) with twelve lags, and we report the more conservative t-statistic of the two. * indicates a p-value of less than 0.1 and ${ }^{* *}$ indicates a p-value of less than 0.05. Data is quarterly and spans 1973Q2-2008Q4. 


\section{Table 9: Robustness: What Explains Real Rate Variation}

Dependent Variable:

(1)

$(2)$

Vol-BM Spread

Duration-BM Spread

$-0.86$

$(-1.14)$

Beta-BM Spread

$6.22^{* *}$

0.84

LR Beta-BM Spread

$4.16^{* *}$

Size-BM Spread

$-2.32^{* *}$

\begin{tabular}{lccccccc} 
Value-BM Spread & \multicolumn{1}{c}{} & & & & 0.86 & $\begin{array}{c}-3.87^{* *} \\
(-2.83)\end{array}$ \\
\hline Controls & $\mathrm{N}$ & $\mathrm{N}$ & $\mathrm{N}$ & $\mathrm{N}$ & $\mathrm{N}$ & $\mathrm{N}$ & $\mathrm{Y}$ \\
Adj. $R^{2}$ & 0.03 & 0.38 & -0.00 & 0.29 & 0.20 & 0.05 & 0.64 \\
$\mathrm{~N}$ & 144 & 144 & 144 & 144 & 144 & 144 & 144 \\
\hline
\end{tabular}

Notes: This table reports regression estimates of the one-year real rate on the spread in book-to-market ratios between high idiosyncratic volatility and low idiosyncratic volatility stocks (Vol-BM Spread). Idiosyncratic volatility is defined as the residual volatility of returns after controlling for exposure to the Fama and French (1993) factors. For all NYSE, AMEX, and NASDAQ firms in CRSP, we compute idiosyncratic volatility at the end of each quarter using the previous sixty days of daily returns. We then form equal-weighted portfolios based on the quintiles of idiosyncratic volatility. Within each quintile, we compute the average book-to-market (BM) ratio. Vol-BM Spread is defined as the difference in BM ratios between the bottom and top quintile portfolios. We also form book-to-market spreads in the same fashion for other sorting variables. The sorting variables we use are: (i) Duration (WEBER); (ii) CAPM Beta, measured using monthly data over rolling 5 year windows; (iii) Cashflow (CF) Beta, which is measured using national income growth; (iv) Long-Run (LR) CAPM Beta, measured using semi-annual data over a rolling ten year window; (v) market capitalization; and (iv) book-to-market ratios themselves (value). Spreads are always between the high quintile and the low quintile of the sorting variable. Controls include Shiller's CAPE, expected GDP growth from the Survey of Professional Forecasters, the aggregate book-to-market ratio, the within-quarter volatility of the three Fama and French (1993) factors, the realized volatility of portfolios sorted on idiosyncratic volatility, and the volatility of TFP growth. Details on all of these variables are contained in the Data Appendix. The real rate is the one-year Treasury bill rate net of one-year survey expectations of the inflation (the GDP deflator) from the Survey of Professional Forecasters. Standard errors are computed using both Newey-West (1987) and Hansen-Hodrick (1980) with twelve lags, and we report the more conservative t-statistic of the two. ${ }^{*}$ indicates a p-value of less than 0.1 and $* *$ indicates a p-value of less than 0.05 . Data is quarterly and spans 1973Q1-2008Q4. All regressions are run in levels and include a constant. 
Table 10: Model Parameters

\begin{tabular}{lcc}
\hline Variable Name & Parameter & Value \\
\hline Share High-Volatility Stocks & $p_{H}$ & 0.20 \\
Discount Rate & $\beta$ & 0.96 \\
Consumption Growth & $\mu$ & 0.03 \\
Lower Bound $G$ & $\lambda$ & 10 \\
Heteroskedasticity Parameter & $\alpha$ & 350 \\
Average $G$ & $\bar{G}$ & 56 \\
Mean-Reversion $G$ & $\kappa$ & 0.01 \\
High Consumption Vol. & $\sigma_{L}$ & 0.01 \\
Low Consumption Vol. & $\sigma_{H}$ & 0.02 \\
Decay Parameter Mark-to-Market & $\rho$ & 0.933 \\
\hline
\end{tabular}

Notes: This table displays the parameter values for the calibrated version of the model in Section 4 . 
Table 11: Model Moments

\begin{tabular}{|c|c|c|c|}
\hline & & Model & Data \\
\hline \multicolumn{4}{|l|}{ Equity Market } \\
\hline Equity Premium & $E\left(r_{t+1}^{e}-r_{f, t}\right)+\frac{1}{2} \operatorname{Var}\left(r_{t+1}^{e}\right)$ & 6.03 & 5.52 \\
\hline Equity Volatility & $\operatorname{Std}\left(r_{L, t+1}^{e}\right)$ & 15.64 & 17.90 \\
\hline Agg. Book/Market Ratio & $E\left(B_{t} / P_{t}\right)$ & 0.63 & 0.62 \\
\hline AR(1) Agg. Book/Market & $A R\left(B_{t} / P_{t}\right)$ & 0.48 & 0.91 \\
\hline \multicolumn{4}{|l|}{ Risk-Free Rate } \\
\hline Risk-Free Rate & $E\left(r_{f, t}\right)$ & 0.72 & 2.40 \\
\hline Std. Risk-Free Rate & $\operatorname{Std}\left(r_{f, t}\right)$ & 1.76 & 1.90 \\
\hline \multicolumn{4}{|l|}{ Low-Minus-High Volatility Portfolio } \\
\hline Vol-BM Spread & $E\left(B_{L, t} / P_{L, t}-B_{H, t} / P_{H, t}\right)$ & -0.01 & -0.23 \\
\hline Std. Vol-BM Spread & $\operatorname{Std}\left(B_{L, t} / P_{L, t}-B_{H, t} / P_{H, t}\right)$ & 0.25 & 0.35 \\
\hline Low-Minus-High Return & $E\left(r_{L, t}-r_{H, t}\right)$ & -1.24 & 1.32 \\
\hline \multicolumn{4}{|l|}{ The Risk-Free Rate and Equity Risk Premia } \\
\hline Slope Risk-Free Rate on Agg. Book-Market & slope $\left(r_{f, t}, \frac{B_{t}}{P_{t}}\right)$ & -1.11 & 2.05 \\
\hline Slope Risk-Free Rate on Vol-BM Spread & slope $\left(r_{f, t}, \frac{B_{L, t}}{P_{L, t}}-\frac{B_{H, t}}{P_{H, t}}\right)$ & 3.35 & 3.36 \\
\hline Slope Return Spread on Lagged Risk-Free Rate & slope $\left(r_{L, t+1}^{e}-r_{H, t+1}^{e}, r_{f, t}\right)$ & 5.22 & 6.02 \\
\hline
\end{tabular}

Notes: Model moments are averaged over 1000 simulations of length 36 years. Simulations use a burn-in period of 20 years. Bold indicates a one-sided p-value $>0.05$. One-sided p-values are computed as the percentage of simulations where the model moments is less than the data moment. The entries corresponding to the risk-free rate and equity risk premia report regression results. For instance, "Slope Risk-Free Rate on Book-Market" reports the estimated coefficient from a regression of the risk-free rate on the aggregate book-to-market ratio. 